\title{
Environmental impacts of natural resource use
}

\section{Book Chapter}

Author(s):

Hellweg, Stefanie (1D; Pfister, Stephan (1D; Cabernard, Livia (D); Droz-Georget, Helen; Froemelt, Andreas (D); Haupt, Mélanie (D); Mehr, Jonas; Oberschelp, Christopher (1D; Piccoli, Emile; Sonderegger, Thomas (1D; Sudheshwar, Akshat; Walker, Christie; Wang, Zhanyun

Publication date:

2019

Permanent link:

https://doi.org/10.3929/ethz-b-000513573

Rights / license:

In Copyright - Non-Commercial Use Permitted

Originally published in:

International Resource Panel, https://doi.org/10.18356/64c3b469-en 


\section{Stefanie Hellweg, Stephan Pfister, Livia Cabernard, Helen Droz-Georget, Andreas Froemelt, Melanie Haupt, Jonas Mehr, Christopher Oberschelp, Emile Piccoli, Thomas Sonderegger, Akshat Sudheshwar, Christie Walker and Zhanyun Wang}

\section{Main findings}

- Resource extraction and processing make up about half of the total global greenhouse gas emissions and more than 90 per cent of land- and water-related impacts (biodiversity loss and water stress). If the rising trend in resource-related impacts persists, it will be difficult to achieve the goals of the Paris Agreement and the Sustainable Development Goals (including SDG 15.5 to halt biodiversity loss).

- Impacts and value creation are not equally distributed around the globe. Per capita impacts of consumption in high-income regions are between three and six times larger than those of low-income regions. This is reinforced by trade: some high-income regions outsource environmental impacts to other regions, such that a part of the total environmental impacts of their consumption occurs abroad. At the same time, the value created through these traded materials in the countries of origin is relatively low.

- Between 2000 and 2015, there was a relative decoupling of resource-related environmental impacts from GDP and a moderate relative decoupling of impacts from extracted mass of resources. However, impacts still increased on an absolute scale. Agriculture is the main driver of global biodiversity loss and water stress, while build-up of infrastructure was the main driver for the increase of climate change impacts. Policy actions are required to maintain the impacts of resource use within planetary boundaries while allowing for development and build-up of infrastructure in developing and emerging economies.

- Potential measures for the simultaneous reduction of agricultural impacts include food waste reduction and shifts in diets towards less meat and animal products from intensive livestock systems. Focusing on longterm material use of sustainably grown wood in the construction sector can lead to co-benefits in terms of climate change and biodiversity. Similarly, conserving valuable forest ecosystems and avoiding deforestation contribute to reducing both climate change and biodiversity impacts.

\subsection{Introduction}

Decoupling economic growth and environmental degradation requires sustainable sourcing and management of resources over the whole life cycle. While the mass-flow indicators of chapter 2 are very useful for understanding the environmental pressures from material consumption, information about the environmental impacts of resource use and resource management practices is also needed to support policymaking for the sustainable use of natural resources (Voet et al., 2005). This chapter focuses on the environmental consequences of resource extraction and processing. It illustrates the legitimate need for appropriate policy to manage natural resources, which is required if we are to remain within the safe operating space (Steffen et al., 2015) and achieve the SDGs. 
Relevant environmental impacts are assessed on the basis of the information on resource extraction provided in chapter 2. The focus is on the resource extraction and processing phase of production, and stops at the "readyto-use" materials and fuels phase (which includes the waste disposal processes in the extraction and processing phase, such as emissions and impacts of mine tailings). As all human activity involves the use of resources, assessing the use phase of all of them would involve assessing the entire global economy. Therefore, while resource extraction and processing are assessed for all resources (denoted as "resource related" and "cradle-to-gate"), the impacts including the use and disposal phase (denoted as "economy wide" and "cradle-to-grave") are discussed only in exemplary cases to highlight the importance of resource quality in the complete life cycle of materials. The cases where the use and disposal phases are considered are presented within a box.

This chapter addresses the "pressure" as well as the "state" and "impact" components of the DPSIR framework. The amounts of resources from the IRP Material Flow Accounting database (part of the "pressure" component) were used as a starting point (chapter 2). For waste and recycling, additional data on recycling amounts were added to complete resource coverage. For each resource, an inventory of emissions and indirect resource consumptions (including land and water resources) was set up, corresponding to the "pressure" component of DPSIR. The data were mainly derived from inventory and input-output databases: Exiobase 3.4 was used to assess the cumulated upstream impacts of all resource types of the whole economy (macroanalysis, Section 3.2) (Exiobase, n.d.; Stadler et al., 2018). Double counting was avoided using an adapted version of the approach by Dente et al. (Dente et al., 2018) (see methodological appendix), assigning the impacts of resources to the final material or fuel (such that the impacts of coal and coke going into steel production would be part of "metal processing" and not "fossil extraction" or "fossil processing"). In addition to the Exiobase "macroanalysis", data were used from ecoinvent 3.4 (Wernet et al., 2016) to study single resources and materials in depth (section 3.3). In these detailed studies, there was no need to aggregate the impacts of various resource types, and therefore no need to correct for double counting. Regional conditions, such as country-specific electricity mixes, were considered where relevant. Finally, the inventory was assessed in terms of environmental and health impacts.

FIGURE 3.1 Overview of methodological procedure to assess the health and environmental impacts of resource extraction and processing. For some resources a complete life cycle perspective was additionally adopted (cradle to grave; these cases are marked by a box)

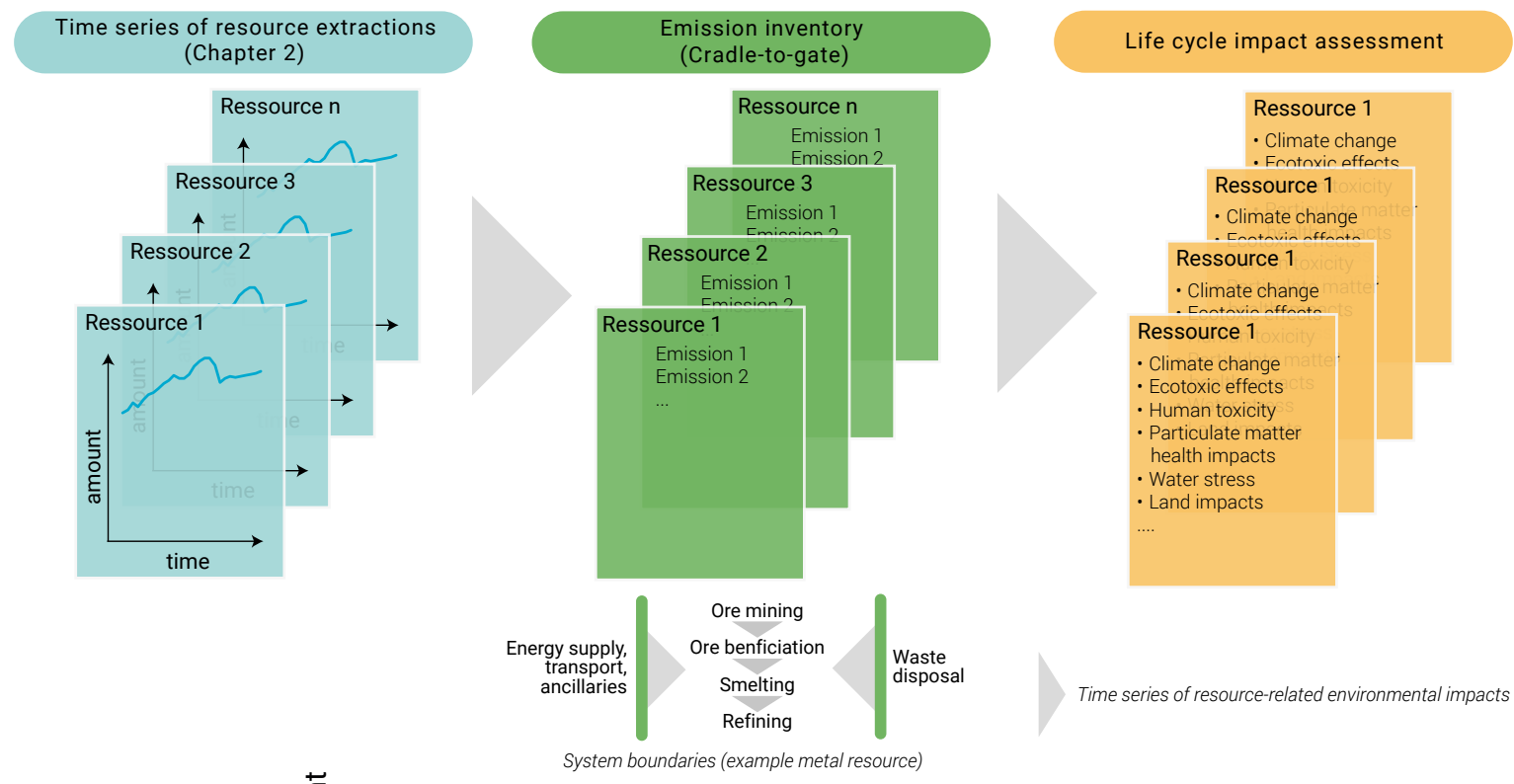


In the impact assessment step, emissions and resource use (for example land and water use) were grouped according to the type of impact they produce and converted to common impact units to make them comparable (Hellweg \& Mila i Canals, 2014). The bestpractice guidelines of the UNEP-SETAC Life Cycle Initiative for use in Life Cycle Assessment were followed (UNEP SETAC, 2016). Recommended methods exist for impacts of climate change (IPCC, 2007), eco-toxicity (Rosenbaum et al., 2008), water stress (Boulay et al., 2018), biodiversity loss from land use (Chaudhary et al., 2016a), human toxicity (Rosenbaum et al., 2008) and human health impacts from particulate matter (PM) exposure (documented in UNEP SETAC, 2016). This impact assessment phase corresponds to the "state" and "impact" components of the DPSIR framework. For example, greenhouse gas emissions were weighted according to the concentration change they produce in the atmosphere (considering persistence and chemical transformations) multiplied by the radiative forcing of the respective gas, a substance property describing how much energy the substance can absorb. This effect of altering the energy balance of the earth is accumulated over a defined time horizon (typically 100 years) and published by IPCC as "Global Warming Potentials, GWPs" (IPCC, 2013). The impacts herein are called climate change impacts, but are also known as the carbon footprint. Note that climate change impacts in this chapter do not include emissions from land use change. For toxicity impacts, the fate of the emissions in the environment is modelled (degradation and partition between environmental media such as water, air and soil) and combined with the substance-specific toxic effects on humans and ecosystems (Rosenbaum et al., 2008). Similarly, for health impacts from emissions of particulates and precursor gases transformed to particulate matter in the atmosphere (SOx, NOx, ammonia), the fate of emissions is modelled in the atmosphere, leading to atmospheric concentration increases of particulate matter. Inhalation exposure leads to elevated risk of cardiovascular and respiratory diseases (ranging in health outcomes from diseases like asthma to increased mortality) (WHO, 2013). Health impacts due to particulate matter exposure and human toxicity are both expressed in terms of Disability

Adjusted Life Years (DALYs), meaning the amount of life years lost or lived with health impairment. Impacts relating to ecosystem damage from land use (causing habitat loss) are expressed in terms of global species loss, such as the fraction of globally existing species that are committed to extinction due to habitat loss (Chaudhary et al., 2015). While this unit does not cover all aspects of biodiversity loss (for example, genetic diversity) or ecosystem services, it remains a highly relevant indicator. Regionalized impact assessment methods were used whenever relevant and possible in order to decrease uncertainties. This was particularly true for the assessment of land and water use, because the magnitude of impacts is not only a function of land area or water amount consumed, but also depends on the location where land and water are used and how they are managed. For example, land use in tropical regions often leads to the extinction of more unique species than land use in less valuable ecosystems. However, a regionalized assessment was not possible for toxicity impacts and only partially for PM health impacts, due to a lack of appropriate regionalized methods (which leads to major uncertainties in terms of such impacts). Interactions between impact categories also exist. For example, the relation between health and biodiversity is extensively discussed in Romanelli et al., 2015.

The selection of impact categories fits well with the "core planetary boundaries" of climate change and biodiversity loss (Steffen et al., 2015), and additionally includes the most relevant pathways for human health impacts from outdoor air pollution (Lim et al., 2012). Furthermore, all these impacts are relevant for resource use, and some of them have been shown to correlate with (and therefore represent) other impacts too. In particular, climate change impacts have been demonstrated to correlate with ozone depletion, acidification and eutrophication for resource extraction and processing (Steinmann et al., 2018). Therefore, these impact categories are not shown separately, unless they diverge from the development of climate change impacts and are predominant with regard to resources (as with phosphorus use as fertilizer and its relation to eutrophication, which is extensively discussed in section 3.3.2).

In order to relate the environmental impacts to economic benefits and social impacts, we also accounted for the value added by the extraction and processing of resources as well as the number of full-time equivalent positions required for this purpose (denoted as "employment" below). Different types of value-added categories as well as the workforce numbers per skill-level are listed for each region and industrial sector in Exiobase 3.4 (Exiobase, n.d.; Stadler et al., 2018). In an additional analysis, "work risks" were quantified using region-sector specific weighting 
factors derived from the social hotspot database (BenoitNorris et al., 2012) to account for social risks (Zimdars et al., 2018). The weighting factors consider human safety, human health, human rights and labour rights, with a view to quantifying the exposure to work risk factors of people working in the resource sectors.

One focus was the assessment of trade impacts. Opportunities include the fact that, ideally, trade and international cooperation could lead to goods being produced where they cause the least environmental impacts and create most social benefits. In many cases, however, profit concerns govern the flow of traded resources and materials, while social and environmental impacts tend to play a secondary role. There is therefore a risk of displacing environmental pressures through trade, with regions consuming resources that were originally extracted and processed in another region. This is considered by presenting results from both a production-based and a consumption-based perspective, as defined in chapter 1.4. We derived "net trade benefits and impacts" from the difference of the production-based and consumption-based perspectives of each respective region (Wood et al., 2018).

More details about the methodological procedure are provided in the method annex. ${ }^{5}$

\subsection{Overview of Impacts of Resource Extraction and Processing}

\subsubsection{Decoupling Resource Impacts from Human Well-being and Economic Growth}

Resource extraction and processing account for more than 90 per cent of global biodiversity and water stress impacts (figure 3.2), and approximately half of global climate change emissions (not including climate impacts related to land use). These results illustrate that resources need to be put at the centre of climate and biodiversity policies,
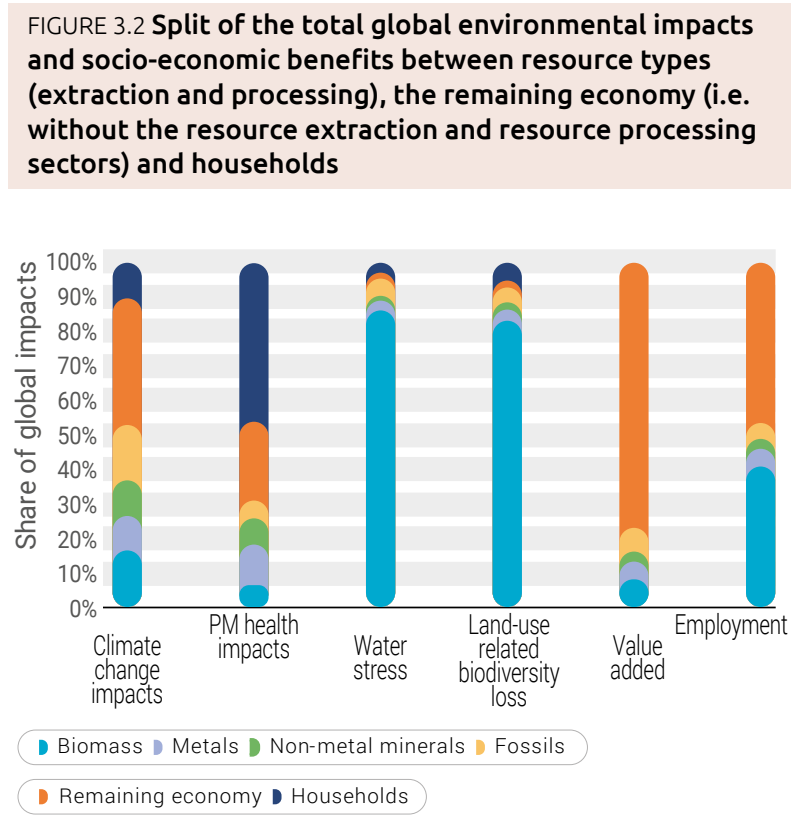

Data sources: Exiobase 3.4 (Exiobase, n.d.; Stadler et al., 2018), combined with landuse data from chapter 2 and impact assessment methods (Section 3.1). Reference year: 2011 so as to stay within the safe operating space(Steffen et al., 2015) and facilitate the achievement of commonly agreed international targets, such as the Paris Agreement, the Aichi targets of the Convention on Biological Diversity and the Sustainable Development Goals (including SDG 15.3 on land-degradation neutrality and SDG 15.5 on halting biodiversity loss).

In contrast to climate impacts, water-stress and landrelated biodiversity impacts, resource extraction and processing make a limited contribution to the global health impacts of particulate matter exposure (figure 3.2) - although these may be relevant on a local scale. Health effects are dominated by combustion-related emissions in the use phase of biomass and fossil resources (figure 3.2). Note that health effects from particulate matter in figure 3.2 exclude indoor emissions, which would increase the share of impacts from "households" even more. In fact, indoor exposure to particulate matter from cooking with solid fuels, particularly biomass, represents one of the most important health risks globally.

Water stress and land use-related biodiversity impacts are mainly caused by biomass resources. This is in contrast to climate change and health impacts from particulate matter, for which all types of resources carry a significant share of the overall impacts (figure 3.2).

Environmental impacts of material provision showed a relative decoupling from economic growth, but per

5 Available at www.resourcepanel.org/reports/global-resources-outlook-2019. 
FIGURE 3.3 Temporal development of environmental impacts from resource extraction and processing (up to "ready-to-be-used" materials or fuels) and socioeconomic indicators from 2000 to 2015
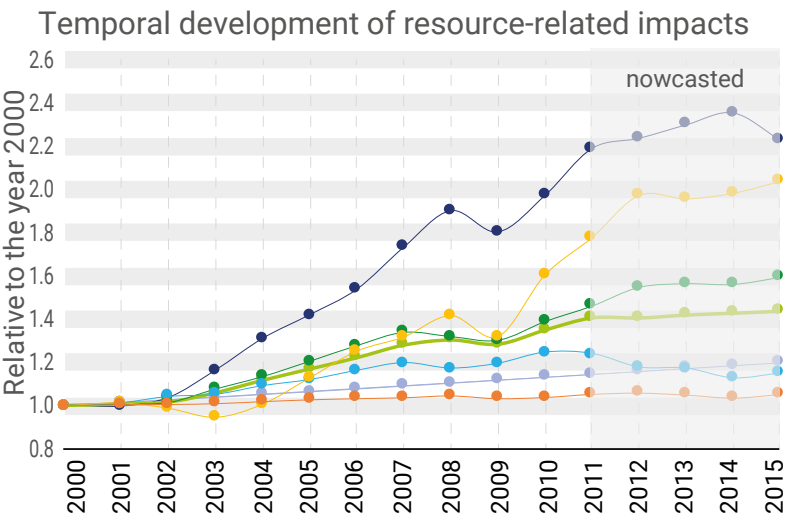

Dopulation GDP (current price) D Climate change impacts

PM health impacts Water stress Value added Employment

Reported data was available between 2000 - 2011, while all Figures after 2011 were "nowcasted" (Tukker et al., 2018); PM: particulate matter; year 2000 = index 1

Data source: Exiobase 3.4 (Exiobase, n.d.; Stadler et al., 2018)

capita impacts increased between 2000 and 2015. In spite of the relative decoupling from economic growth, all impacts increased in absolute terms in comparison to the year 2000 (figure 3.3). The temporal trend of biodiversity impacts from land use has already been discussed in a previous IRP report (IRP, 2017a) and was found to increase on an absolute scale, while the geographical impacts and changes are discussed in section 3.3.6, based on new land use data (chapter 2). The new data did not make it possible to assess the temporal trend, as the land use maps only showed the predominant (not total) land use per grid cell (the uncertainty is larger than the changes in impact).

Resource-related value added per GDP showed an increasing trend between 2009 and 2011 (end of reported data), while all environmental impacts per GDP decreased in this time period (figure 3.3). This is a positive development, as sector specific value-added increased by a greater extent than GDP, and environmental impacts were decoupled (relatively). Nonetheless, resource extraction and processing generate a low share of economy-wide added value (<23 per cent), while providing work to approximately 50 per cent of the global workforce (mainly through agriculture) (figure 3.2). The number of workplaces remained rather constant over time (Figure 3.3), in spite of the increase in resource use, due to increasing labour productivity.

\subsubsection{Impacts by Region and the Role of International Trade}

Per capita impacts caused by consumption of highincome countries are between three and six times larger than those of low-income countries (figure 3.4, left). This

FIGURE 3.4 Left: Per capita impacts (climate change impacts, PM health impacts, water stress, land-use related biodiversity loss) and socio-economic benefits (value added, employment) by income group (consumption perspective). Right: Global net trade impacts per capita ordered by income group countries, represented as a share of global per capita impact.
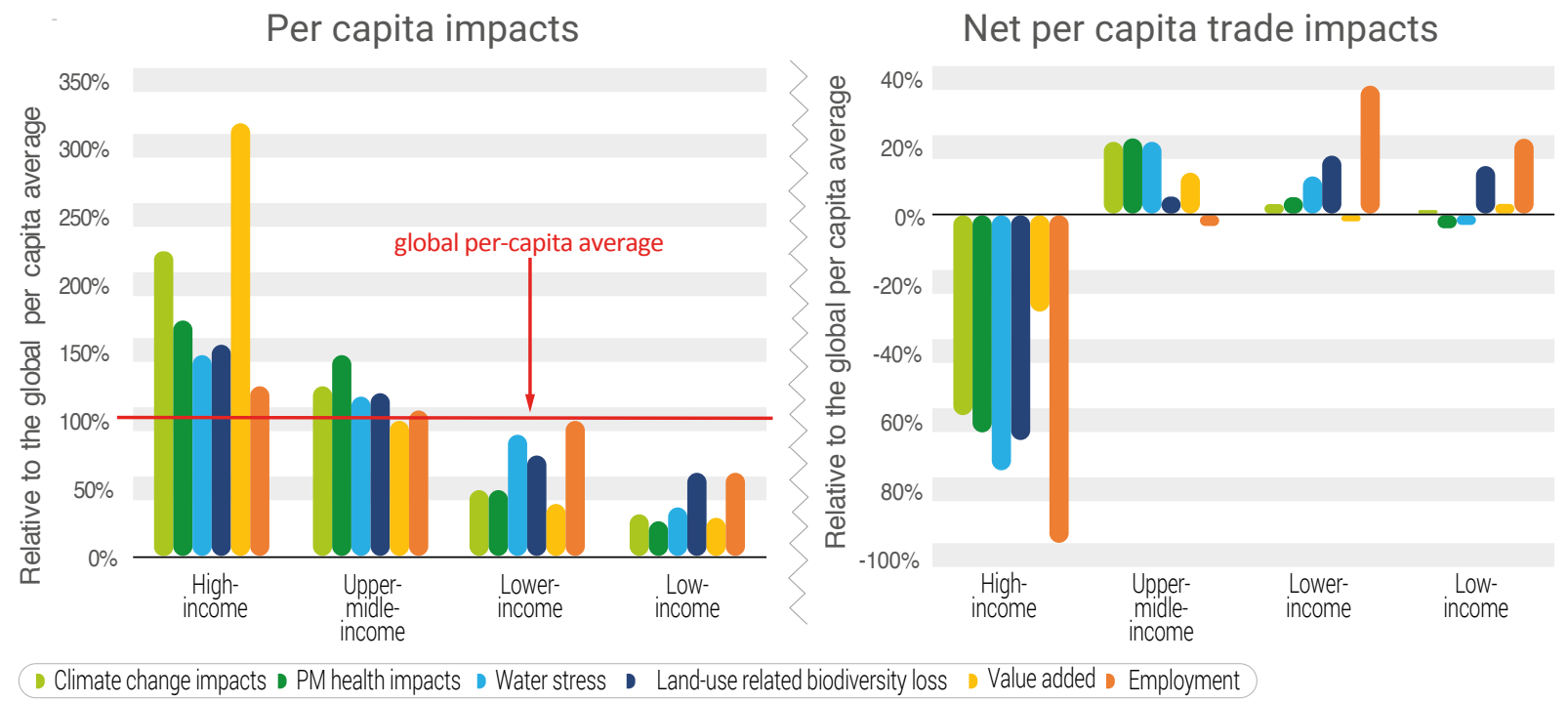

D Climate change impacts PM health impacts Water stress L Land-use related biodiversity loss Value added Employment

Notes: Left: The 100 per cent line marks the global per capita average impact. Right: Negative values refer to an outsourcing of environmental impacts or value/workplace creation to other regions, positive values refer to environmental impacts occurring in the region of the production of export materials. Reference year: 2011

Data source: Exiobase 3.4 (Exiobase, n.d.; Stadler et al., 2018). 
FIGURE 3.5 Impacts (climate change impacts, PM health impacts, water stress, land use-related biodiversity loss) and socioeconomic footprints (value added, employment) attributed to the region of consumption
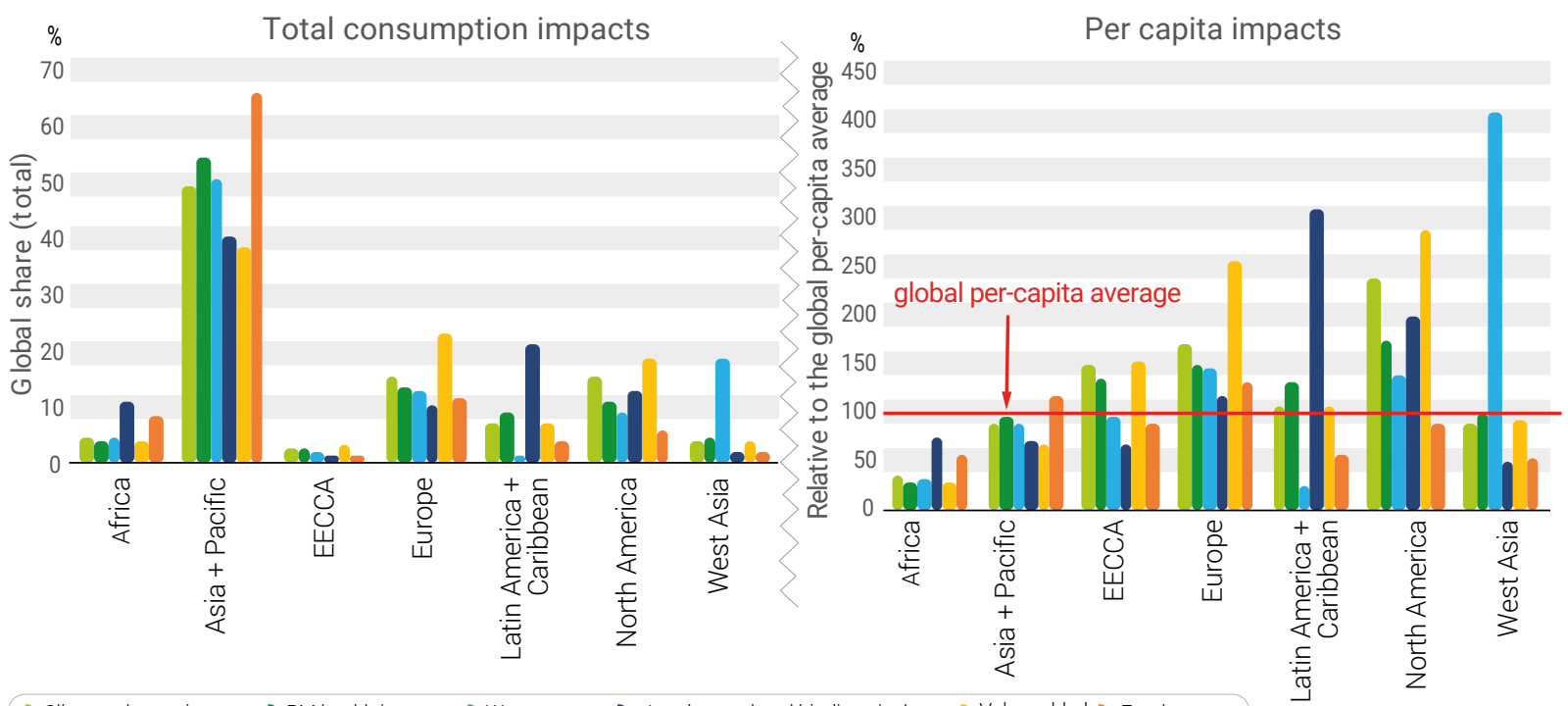

D Climate change impacts PM health impacts Water stress

Left: Total footprints as a share of total global impacts (values for all regions together add up to 100 per cent).

Right: Per capita footprint, where the 100 per cent line marks the global per capita average. Reference year: 2011

Data source: Exiobase 3.4 (Exiobase, n.d.; Stadler et al., 2018).

illustrates the unequal contribution that the consumption of richer and poorer regions make to global environmental impacts. Water and land impacts show a smaller variation between income groups than climate change and PM health impacts. This is because they are mainly related to food consumption, and food intake is less variable than fuel or material use between income groups. Furthermore, high-income regions import resources and materials and outsource environmental impacts from production to middle- and low-income regions (figure 3.4, right).

The total footprints of the world regions vary by more than one order of magnitude, mainly due to the different sizes of regions (figure 3.5 left). ${ }^{6}$ Asia and the Pacific has the largest footprints (more than half of the global climate, PM health and water-stress impacts). Climate change and PM health impacts show a similar pattern in regional footprints, while water stress and land use related biodiversity loss diverge from this pattern (figure 3.5). This is mainly caused by the spatial variability of the water and land use impacts of biomass production, which depend on the climate and ecoregion conditions, in addition to production efficiency and consumption.

The per capita footprints show that some regions consistently cause above-average impacts through consumption (Europe and North America), while other regions only have minor per capita consumption-related environmental impacts (particularly Africa) (figure 3.5, right). However, impacts do not always show the same trend. For example, West Asia generally displays belowaverage consumption impacts, but shows above-average impacts in terms of water stress due to the large-scale domestic irrigation required by the climate and the intensive agricultural activities. A similar, above-average deviation in the impacts applies to land use-related biodiversity loss in Latin America, which is due to the impact of domestic agriculture on valuable ecosystems.

The climate change impacts of most world regions are mainly caused by private consumption (figure 3.6, and annex for PM health impacts), while capital formation plays a small role, either because the infrastructure has already been built up in the past (for example North America and Europe) or because infrastructure has not been fully built up yet (for example Africa). This is different in Asia and the Pacific, where build-up of infrastructure is the main driver of impact (figure 3.6). The latter is caused primarily by recent development in the People's Republic of China. China is the country with the highest resource-related climate change and PM health footprints in the world, although per capita

6 In Chapter 3, Iran is included in West Asia and Mexico is included in North America. 
FIGURE 3.6 Climate change impacts split according to final demand categories.

Total climate change impacts

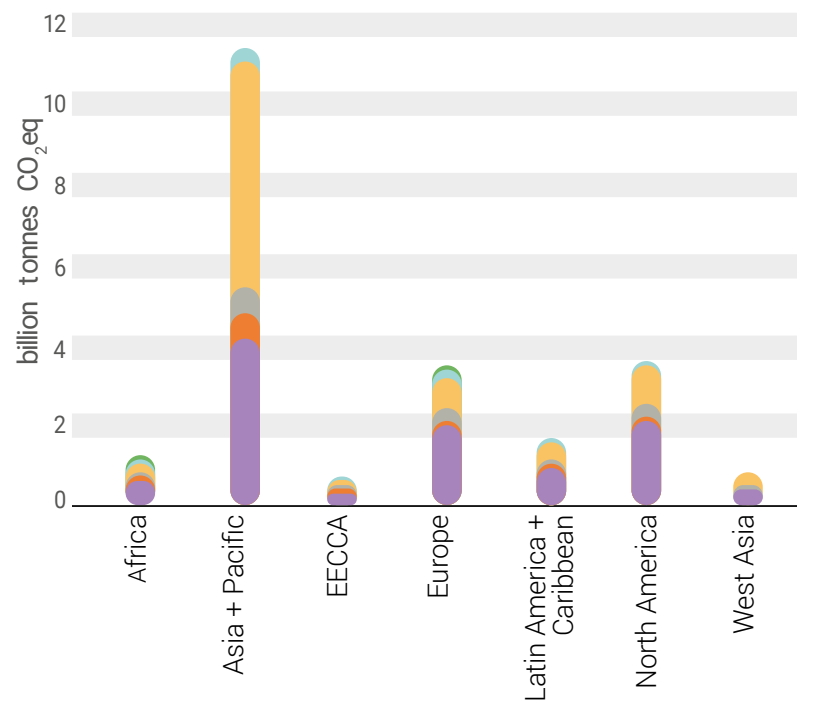

Changes in valuables Changes in inventories

D Capital formation (infrastructure build-up) D Government expenditures

D Non-profit organisations serving households D Household consumption

Note: Total impact by region (year 2011);

Data source: Exiobase 3.4 (Exiobase, n.d.; Stadler et al., 2018)

impacts are in line with or even below the global average. As of 2011, over 65 per cent of all impacts and 80 per cent of all infrastructure development impacts in the Asia and the Pacific region were contributed by China. The overall footprint for climate and PM health impacts has increased substantially in the past 15 years and can be explained by the buildup of infrastructure, especially as regards climate impacts. This infrastructure build-up represents a long-term investment, and many developing countries are likely to follow this pattern of increased infrastructure investment in the future. Therefore, policy actions are required to maintain the impacts of resource use within planetary boundaries while still allowing for development and build-up of infrastructure in developing and emerging economies.

Water stress and land-related biodiversity loss are mainly caused by household food consumption in all regions (see annex), although capital formation can play a significant role in some sub-regions (for example due to wood used to build up infrastructure in the south-east of Asia).

Globally, resource-related climate change footprints associated with consumption converged, with per capita high-footprint regions lowering their impacts at the same time that low-footprint regions increased their impacts. Lower impacts in high-footprint countries suggest efficiency gains in production, but were also affected by the financial crisis and the associated reduced consumption (figure 3.7).

Figure 3.8 provides an overview of the regions that are net exporters or net importers of resource-related environmental pressures and socioeconomic benefits (following the method of Wood et al., 2018). Europe and North America show higher footprints for all impact categories than domestic impacts due to their comparatively higher consumption than production of biomass, metals and particularly fossils (figures 3.8 and 3.9). These regions therefore "outsource" impacts to other regions, while creating only minor economic benefit (in terms of value added) in the countries of origin (figure 3.10).

West Asia and Asia and the Pacific have the largest water-stress impacts, while Latin America and Asia and the Pacific have the largest land use-related impacts, due to their unique ecosystems. For all these regions,

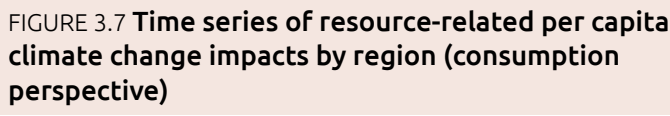

Per capita climate change impacts

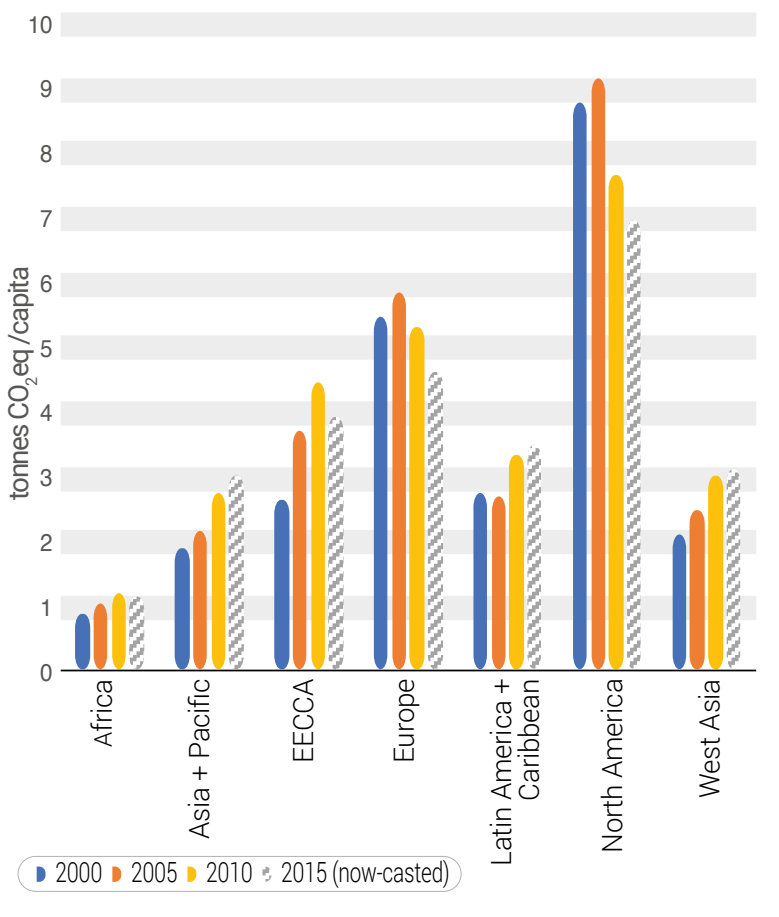




\section{BOX 3.1 Life Cycle impacts of household consumption (including the use phase of resources)}

On an individual country level as well as on a global level, numerous studies have consistently identified three major consumption hotspots that are crucial from an environmental point of view: mobility/transport, food and housing/shelter (for example, see Hertwich \& Peters, 2009; Tukker \& Jansen, 2006). However, there is considerable variability in behaviours among households from different countries but also within each country. Consequently, the relative scale and absolute amounts of emissions in different consumption areas differ from country to country, as well as among socioeconomic groups. For instance, basic needs such as food or shelter have a relatively higher share of total impacts in lower income countries, while mobility is especially relevant in high-income economies (Hertwich \& Peters, 2009). In cross-country comparisons, GDP is considered the most informative explanatory factor for national per capita carbon footprints (Hertwich \& Peters, 2009) and material or land use footprints (Ivanova et al., 2016). Similarly, income distribution can explain much of the variability in household environmental footprints within countries (Baiocchi et al., 2010). Many studies show a macrotrend of a positive relationship between income and environmental impacts (Baiocchi et al., 2010; Jones \& Kammen, 2014; and Weber \& Matthews, 2008). This is also shown by Froemelt et al., 2018, for the case of Switzerland, but they additionally reveal that some household groups diverge from these general tendencies indicating a certain decoupling. Low-impact households in industrialized countries were found to opt for higher priced goods, less mobility and green heating (for example heat pumps or wood-based technologies) (Girod \& De Haan, 2009). A relative decoupling effect was also found for the top income quintile in the European Union (Sommer \& Kratena, 2017). However, this does not offset the much higher impacts caused by these high-income households.

Apart from income, household size and location (rural versus urban) are often analysed as factors influencing household behaviours and associated environmental impacts (Baiocchi et al., 2010; Hertwich, 2011; Tukker et al., 2010). The economy of scale originating from household size appears in many studies: the larger the household, the lower its per capita footprint. However, at a certain income level, this trend is less pronounced (Froemelt et al., 2018; Underwood \& Zahran, 2015; Weber \& Matthews, 2008). The influence of household size is especially significant in view of the decreasing number of persons per household in industrialized countries (Underwood \& Zahran, 2015). In contrast to household size, the impact of location is less distinct. In general, households in dense urban areas tend to have lower impacts, especially in the domains of mobility (shorter distances) and housing (smaller apartments) (Baiocchi et al., 2010; Tukker et al., 2010; Wiedenhofer et al., 2018). This, however, is partially offset by smaller household sizes and higher incomes in cities (Jones \& Kammen, 2014; Wiedenhofer et al., 2018), although the latter greatly depends on the national context (Baiocchi et al., 2010) . Furthermore, Jones \& Kammen, 2014 reveal that high-density areas in the United States of America do indeed show lower environmental footprints for households. However, the suburbs around these central metropolitan areas can erode this effect and even lead to increased impacts in the area as a whole. Note that studies seeking to understand these drivers of household environmental footprints focus mostly on high-income countries and may therefore not be applicable to developing economies.

In conclusion, the environmental impacts of different lifestyles are affected by a multitude of factors and therefore show high variability in terms of total amounts and composition, not only among different countries (Hertwich \& Peters, 2009; Ivanova et al., 2016) but also among different household types (Baiocchi et al., 2010; Jones \& Kammen, 2014) and even within socioeconomic household segments (Froemelt et al., 2018; Saner et al., 2013; Weber \& Matthews, 2008). Even though some general trends, such as increased impacts with increased income, or consumption hotspots (like food, mobility and housing) can be identified, this highly complex situation reveals that there is no one-size-fits-all solution to support a pathway towards low-impact consumption patterns (Froemelt et al., 2018; Jones \& Kammen, 2014). For a successful change towards more sustainable lifestyles, measures, policies and programmes aiming at reducing the impacts of households should be tailored as much as possible to the target region or even to the target household groups (Froemelt et al., 2018).

the production-related impacts inside the region are higher than the consumption impacts (figure 3.8), due to the export of agricultural products. Europe is the largest beneficiary, as it imports agricultural products from waterscarce regions.

Total resource-related greenhouse gas emissions and PM health impacts are largest in Asia and the Pacific (figure 3.9). Asia and the Pacific, EECCA and West Asia have higher domestic climate impacts than consumption footprints due to their importance in the extraction and processing of fossils (figures 3.8 and 3.9). For PM health impacts, metal processing additionally contributes to this effect in the case of EECCA.

Making the electricity system more renewable (as outlined in SDG 7.2) will lower the climate impact of resource extraction and processing, since greenhouse gas intensity per kWh electricity decreases. However, such a decrease in climate impact will be limited as the 
FIGURE 3.8 Net trade impacts by region, calculated as the difference between production-based and consumption-based footprints
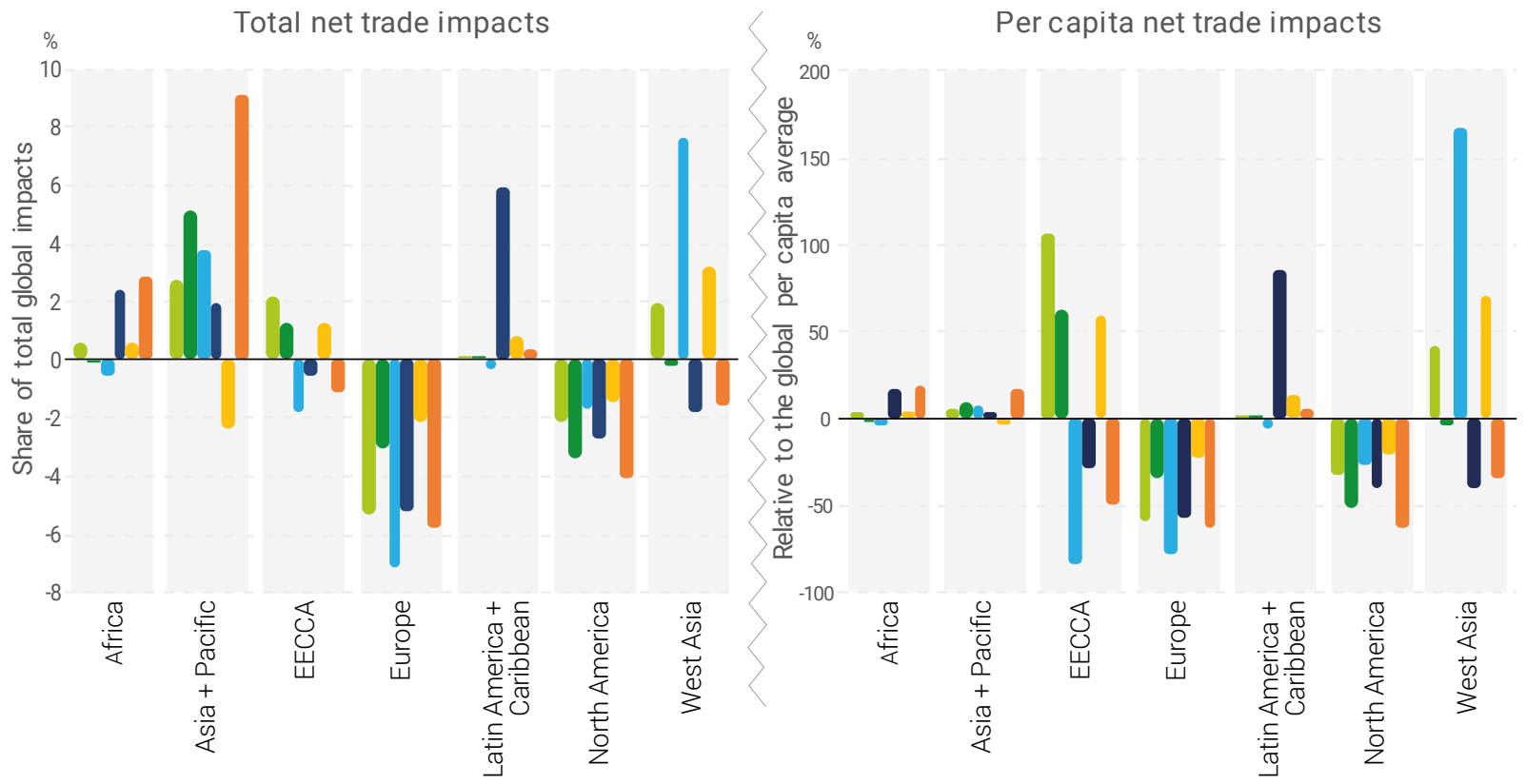

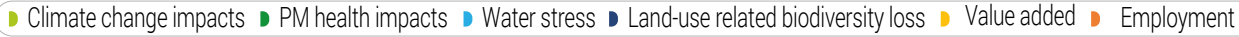

Notes: Left: Total net trade impacts represented as a share of total global impacts; Right: Per capita net trade impacts relative to the global per capita average impact. Negative values refer to an outsourcing of environmental impacts and socio-economic benefits to other regions, positive values refer to environmental impacts and socio-economic benefits occurring in the region of the production of export materials. Reference year: 2011

Data source: Exiobase 3.4 (Exiobase, n.d.; Stadler et al., 2018)

contribution of electricity inputs to the impacts of resource extraction and processing is already just 10 per cent (data not shown; calculated from Exiobase 3.4). Furthermore, renewable electricity demands more metal and non-metal mineral resources, which will increase the climate impact of resources (IRP, 2017c). The combined impacts of an increased renewable future energy system are discussed in a separate IRP report (UNEP, 2017).

Per-capita added value is largest in Europe and North America (figure 3.10). Europe generates 20 per cent of the global resource-related value added, but only 5 to 10 per cent of the environmental impacts occur there. In contrast, as an example, 24 per cent of the global water stress impacts, 8 per cent of climate change impacts, 7 per cent of PM health impacts and 7 per cent of land use biodiversity impacts arise in India, but only 4 per cent of the resource-related value added is generated there. This inverse pattern of domestic resource-related value added and environmental impacts may be a sign of varying environmental standards, but may also indicate the unequal distribution of resource-related benefits and impacts. This is reinforced by international trade, as discussed above.
There is considerable variation in the dependence of world regions on the resource sector. Employment in the resource sector is especially high in Asia and the Pacific, where more than 40 per cent of all people work in resource extraction and production sectors - mainly in biomass production (figure 3.10). In North America, less than 10 per cent of the population works in this sector. The comparison between the consumption and production perspective shows that many people in Asia and the Pacific or Africa work for the production of resources (mainly biomass) that are consumed in regions such as Europe, North America and West Asia (figure 3.10).

Full, productive employment and decent work is a requirement under SDG 8.5. Figure 3.11 shows the distribution of workplaces, the value added, as well as the salaries (compensation of employment) in the material production sector. There is considerable variability among the world regions in terms of these indicators. While high levels of employment are indeed positive for achieving the SDGs, the work risks (adverse work conditions based on the social hotspot database; see section 3.1 and annex) also need to be considered. For regions with high relative shares of employment compared to value added (such as 
low- to middle-income regions), these risks are higher than in the regions with a high share of value added compared to occupation. Improved working conditions and increased salaries in the resource sectors of low- and middle-income countries are therefore important steps in achieving the aim of decent work enshrined in SDG 8.5.

Human well-being is often measured by the human development index (HDI), which includes aspects relating to GDP, health and education. Patterns of production-related water and land impacts on subnational administrative units were analysed for various classes of HDI (figure 3.12). Regions with very high human development indices ( $\mathrm{HDI}>0.8$ ) combine just 6 per cent of global population with 50 per cent of GDP, 11 per cent of biodiversity loss due to land use and 8 per cent of global water scarcity. The majority of the impacts occur in regions of HDI 0.6-0.8 (middle to high human development), with 27 per cent of global population, 42 per cent GDP but 63 per cent biodiversity loss and 65 per cent water scarcity (mainly due to biomass cultivation). Many areas with an $\mathrm{HDI}<0.4$ are situated in central Africa, where irrigation is all but absent and biodiversity loss is relatively low. This reflects low economic development in this region.
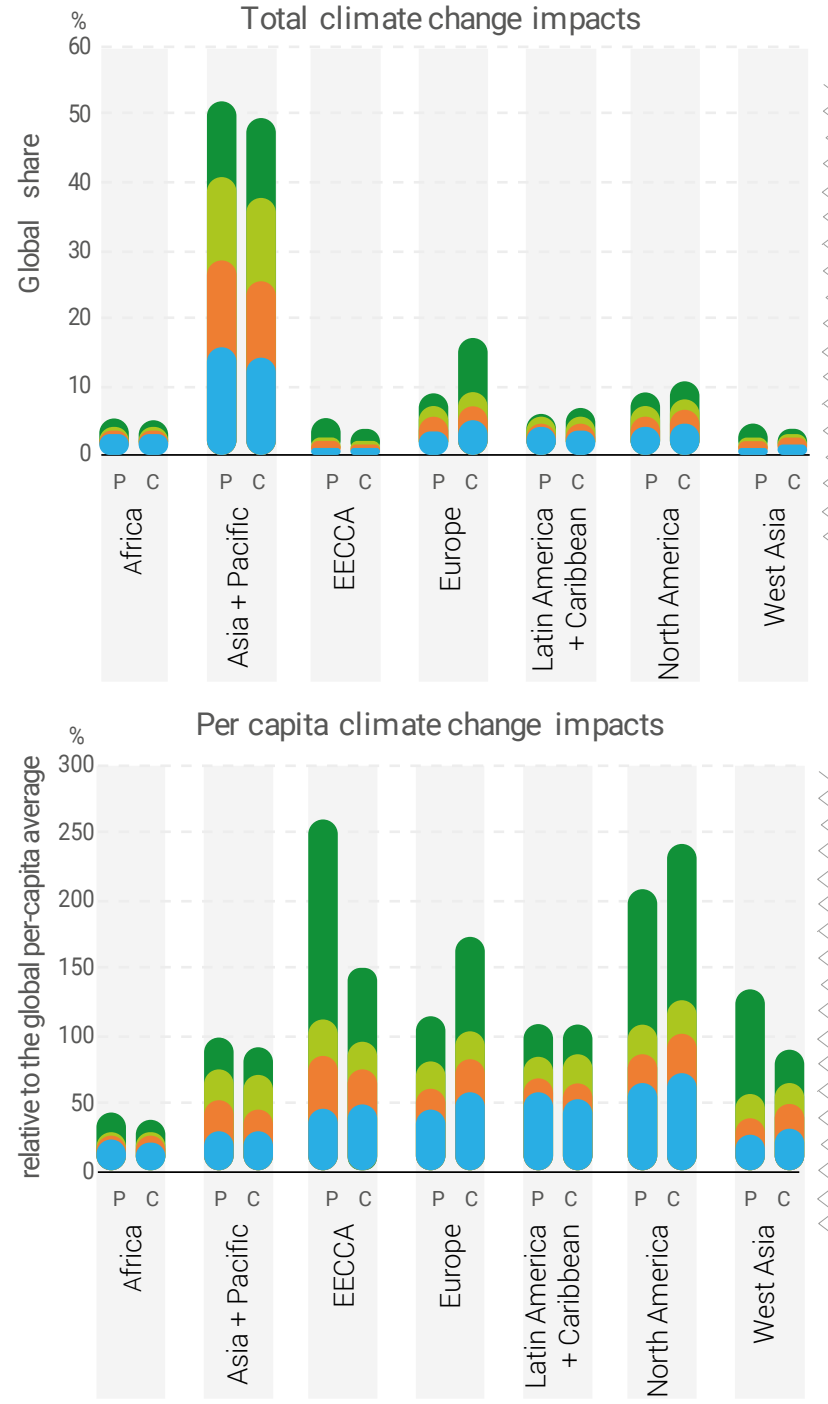

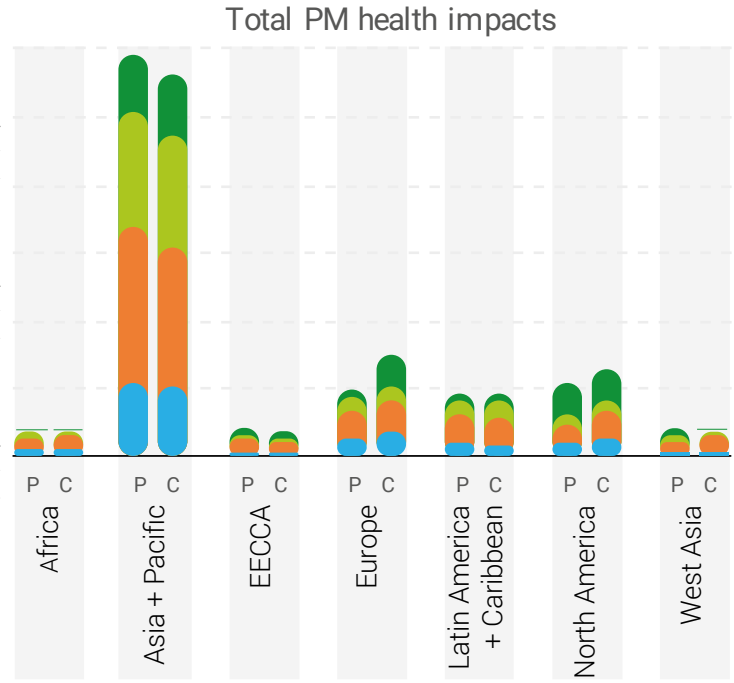

Per capita PM health impacts

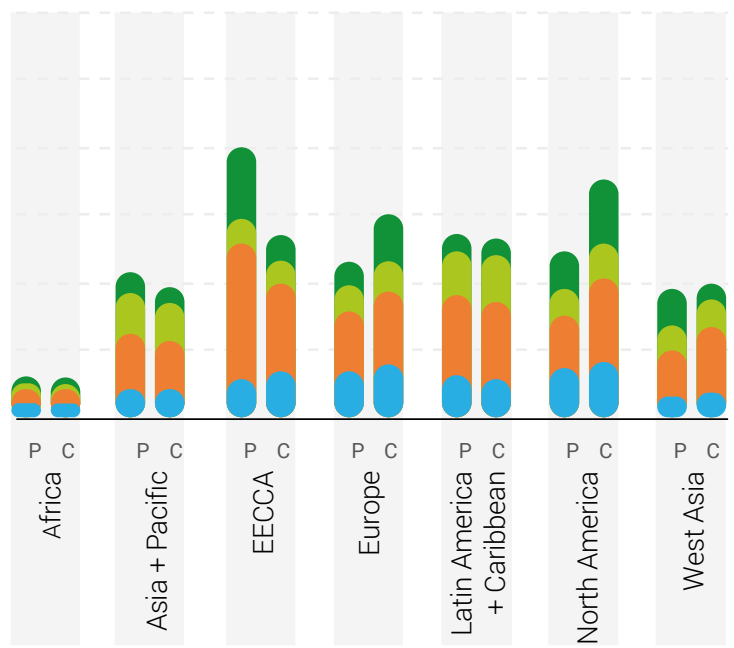

Biomass Metals Non-metal minerals Fossils

Notes: Left: Left: total impacts; Right: Per capita impact; P: production perspective, C: consumption perspective. Data sources: Exiobase 3.4 (Exiobase, n.d.; Stadler et al., 2018) 

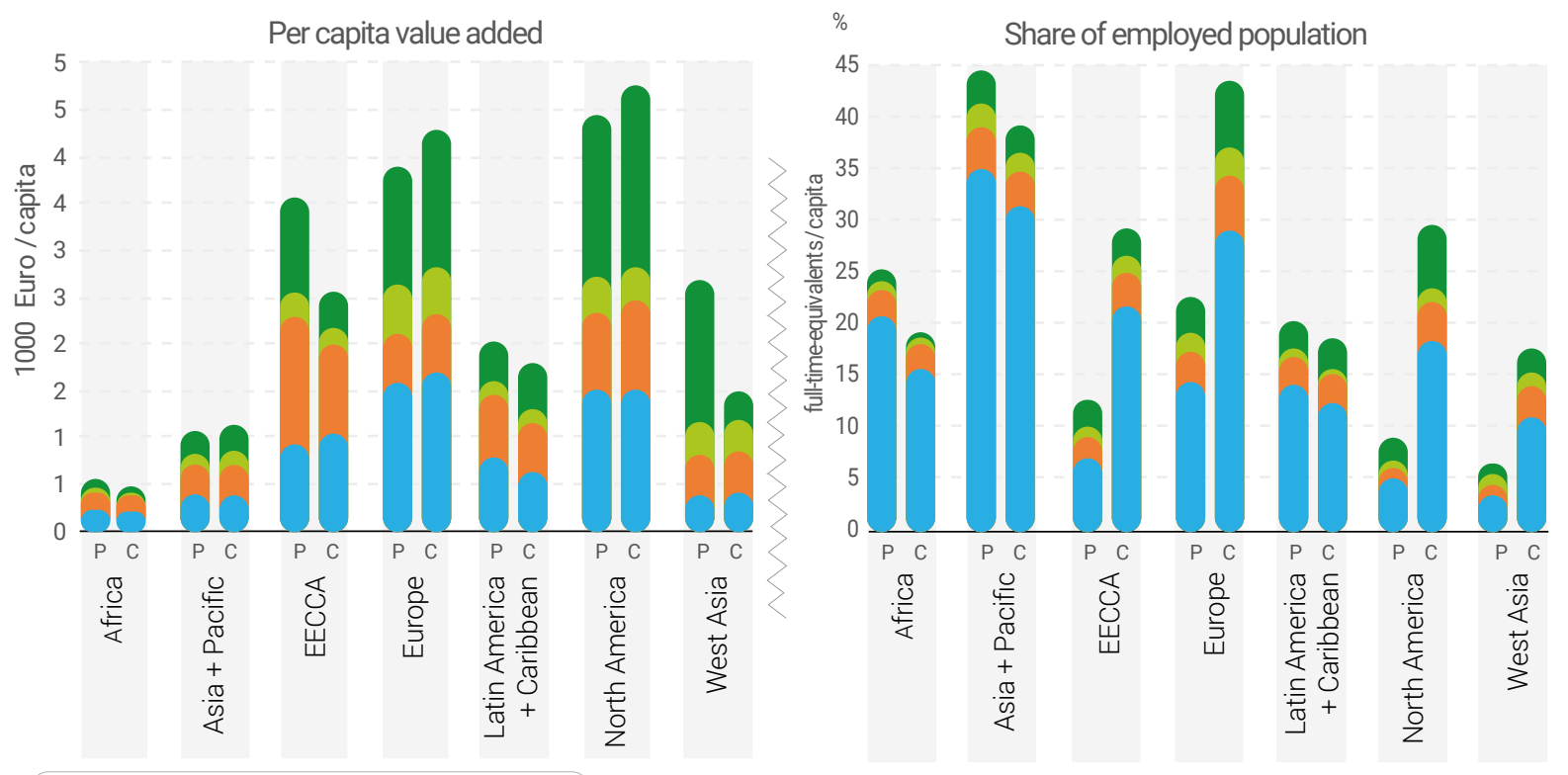

Diomass Metals Don-metal minerals Fossils

Notes: Left: Share of population working in the resource sector (full-time-equivalents per capita); Right: Value added (Euro) P: production perspective, C: consumption perspective. Reference year: 2011.

Data sources: Exiobase 3.4 (Exiobase, n.d.; Stadler et al., 2018)

FIGURE 3.11 Global share of total value added, value added for compensation of employment (salaries), and number of employed people related to material production

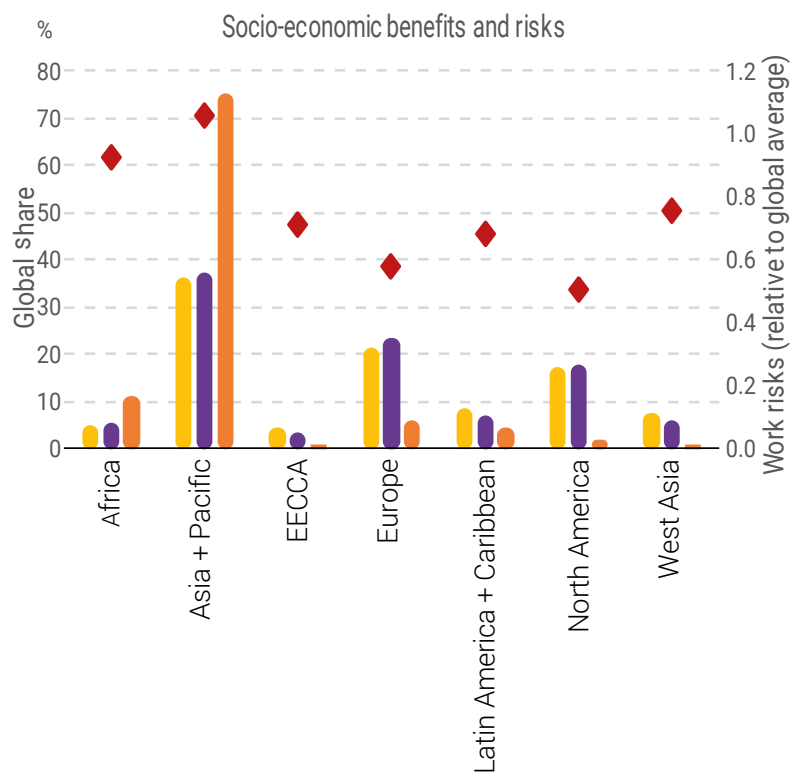

Value Added Compensation of Employment Employment

\section{Work Risk Factor}

Notes: Left axis: Values for all regions together add up to 100 per cent; Right axis: Work risks, where a factor of 1 corresponds to the global average (details in annex). Reference year: 2011
FIGURE 3.12 Global share of GDP, population and impacts of water stress and land use-related biodiversity loss in the production perspective (Biodiversity Loss Land use)

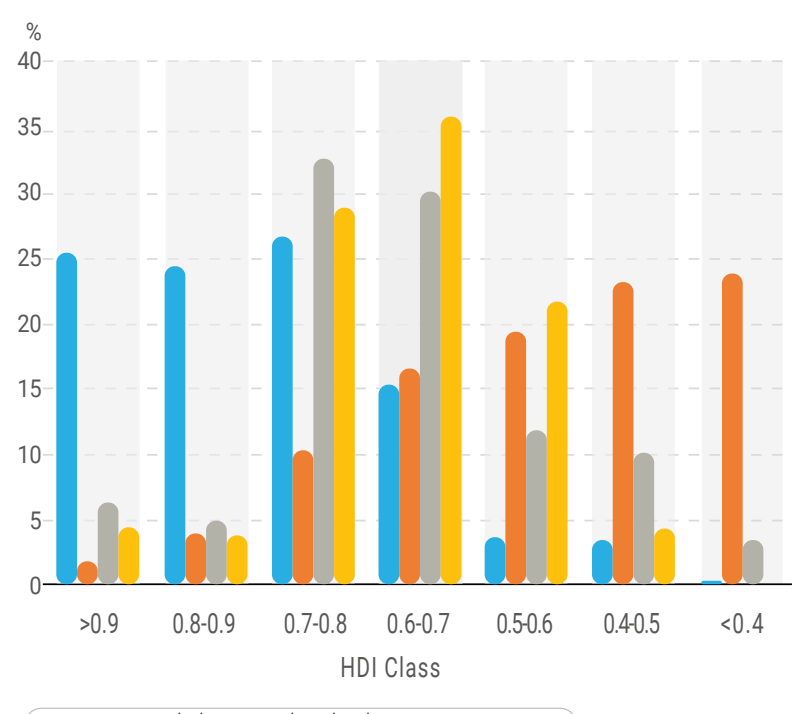

GDP Population BD loss land use Water stress

Classified by human development (HDI class, $x$-axis). The impacts were calculated on subnational administrative units based on data from (Kummu et al., 2018) with the same geographies for local HDI, GDP and population data. 


\subsection{Environmental and Health Impacts by Resource Group}

This section opens with a discussion of the contribution of four material resource groups (metals, non-metallic minerals, fossils and biomass) to the environmental impacts of climate change, ecotoxicity, human toxicity and human health impacts from primary and secondary particulate matter emissions (sections 3.3.1 to 3.3.4). The extraction, processing and use of these resources leads to another indirect resource use, namely water consumption and land use. The resulting impacts of water stress and biodiversity loss from land use are extensively discussed at the end of the section (sections 3.3.5 and 3.3.6). Each section contains an in-depth discussion of those resources that contribute most to impacts and have the highest leverage in impact mitigation.

\subsubsection{Impacts of Metal Resources}

Metals are essential for the kind of technology that underpins modern society. From structures and industrial equipment to information technology, virtually all activities and products rely on metals, at least indirectly. However, the extraction and processing of metals from mined ores have an associated environmental cost. In 2011, metals were responsible for 18 per cent of resource-related climate change and 39 per cent of PM health impacts (figure 3.2). Considering the period 2000-2015, the climate change and PM health impacts of metals more or less doubled. Toxicity impacts also increased in the same time period, but at a slower pace (figure 3.13).

Steel is the most widely used metal, mainly as a construction and engineering material, because of its good mechanical properties and affordability. Among metals, the global iron-steel production chain causes the largest climate change impacts (figure 3.13). This is due to the large volumes of steel produced yearly and the energy-intensive processing of the ore into iron and steel, with the sector representing around one quarter of global industrial energy demand. Further significant contributions to the total climate change impacts of metals arise from aluminium production (figure 3.13), again due to considerable production amounts and high energy requirements for the smelting of aluminium via electrolysis.

The mining and processing of copper and precious metals cause high toxicity impacts compared to their production amounts (figure 3.13). Sulfidic mining tailings are the main source of toxicity impacts for both metals. Processed materials are stored in tailing impoundment dams, but can nevertheless involve continuous leaching of pollutants into the soil and groundwater and might additionally present risks of contamination from spills in case of failure (Beylot \& Villeneuve, 2017). The predominant contribution of tailings to toxicity impacts can also be related to the large amounts of rock processed per mass of refined metal. Gold and precious metals are mined at much lower concentrations than bulk metals such as iron or aluminium. As physical separation methods typically require higher ore grades, sodium cyanide compounds have been used for more than a century in the industrial extraction of gold, with an estimated 18 per cent of world cyanide production dedicated to the formal gold mining sector (Hilson \& Monhemius, 2006). Since cyanide degrades spontaneously in the environment, the risks associated to its use consist mainly in the sudden release of this pollutant, which can be averted with careful management of waste streams.

Recycling represents one possible pathway towards decreased environmental impacts deriving from metal use. Metals are ideal candidates for closing material

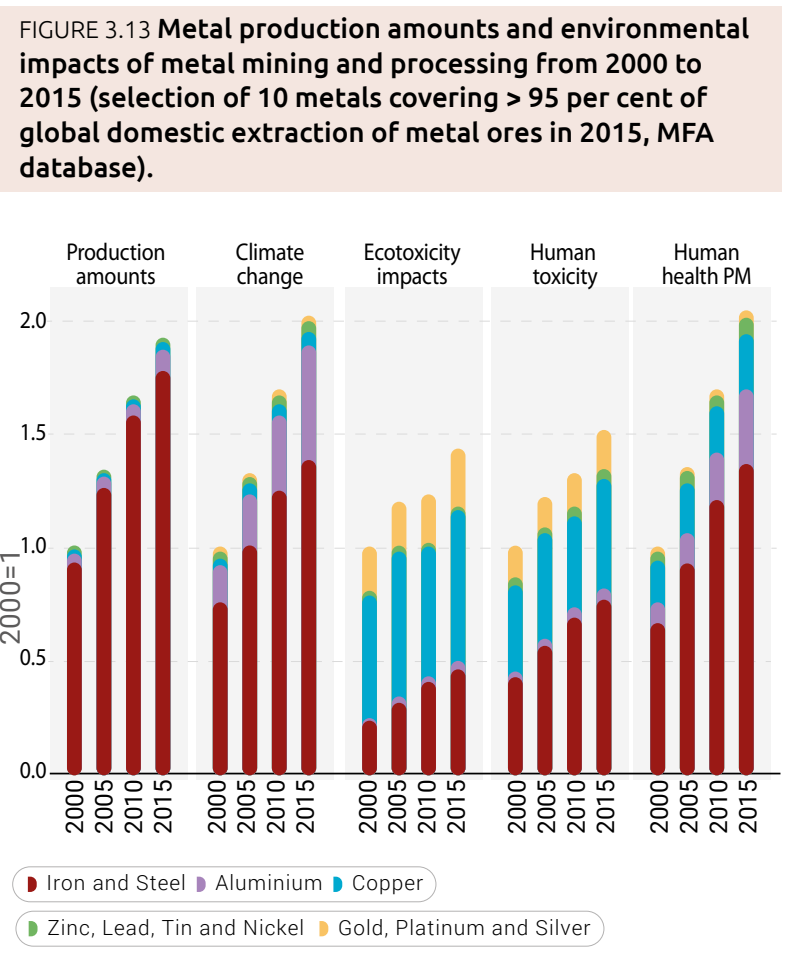

Data sources: BGS, USGS, ecoinvent 3.4, World Steel. Note that secondary aluminum was not included for the ecotoxicity score due to a mistake in ecoinvent 3.4 . 
loops in a circular economy approach, because they can be melted and reused indefinitely (as long as alloys are not contaminated by weakening or toxic elements). In general, secondary production considerably reduces the environmental impacts of metal use, because it avoids the impacts from the extraction and processing of ores. For example, the climate change impacts of steel recycling are between 10 and 38 per cent of that of primary production and for aluminium recycling between 3.5 and 20 per cent (figure 3.14). This variability is mainly explained by the difference in the electricity mixes among countries: the lowest impacts occur in countries with renewable electricity mixes - such as Norway, Iceland and Canada while India and China display the largest per-kg impacts (see annex). However, metals such as steel are used in many products with long lifetimes (for example in the construction sector), so that the scrap amounts available today for recycling correspond to a share of the production amounts that entered the market many years ago. Taking steel as an example, this characteristic coupled with increasing demand means that the amounts of scrap steel

\section{FIGURE 3.14 Climate change impacts of metal recycling} versus primary production

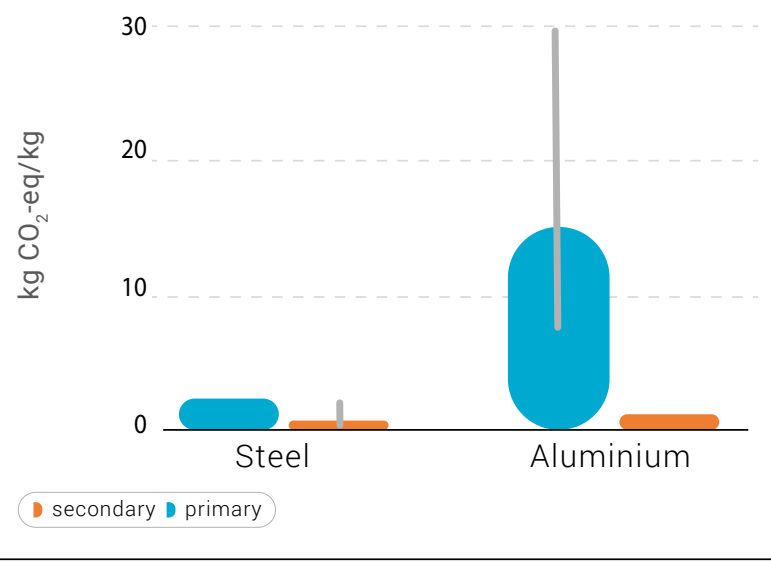

The uncertainty bar captures the variation in CO2-emissions of electricity mixes of the producing countries (see annex). Country-adapted cradle-to-gate impacts from ecoinvent 3.4.

available are unable to match the large global increase in steel demand (figure 3.15). As a result, increase in demand is covered mainly by primary steel, thereby decreasing the overall share of secondary steel. In 2000, electricarc furnaces (EAF) suitable for secondary steel covered 34 per cent of global crude steel production, while in 2015 this share fell to 25 per cent (World Steel Association, 2017). This trend was most visible in China, which has become the world's top steel producer, and contributed more than half of the sector's greenhouse gas emissions in 2015. Its primary steel production increased more than six times between 2000 and 2015, while the share of EAF decreased from 16 per cent in 2000 to 6 per cent in 2015 . This is in contrast to "old economies", such as Europe, where the bulk of the infrastructure was built up a long time ago and both demand and recycling rates are on a steadier trajectory. However, approximately 20 per cent of the Chinese climate change impacts from the iron-steel industry are due to exports to other regions (Exiobase, n.d.; Stadler et al., 2018). Globally, while steel recycling is a good way of lowering the impacts of steel production and recycling should be increased, its overall potential is limited by the availability of scrap. In the context of expanding demand over the medium term, this limitation will remain an important constraint in the coming decades (Van der Voet et al., 2018).

In the primary production route of steel, the first processing steps account for more impacts than the iron ore extraction phase for all indicators. The overall energy efficiency of iron- and steel-making rose considerably in the last few decades of the 20th century, but plateaued in the course of this century (IEA, 2014; World Steel Association, 2018). Today, blast furnaces are the most widely used technology, but some outdated open-hearth furnace plants still exist. The latter have much larger climate change impacts compared to all other technologies. In a blast furnace, the heat and elemental carbon required to smelt iron from raw materials is primarily provided by the combustion of carbon coke (Hasanbeigi et al., 2014). This process step accounts for most of the climate impacts of the primary steel value chain. Alternatives to the blast furnace production route offering lower carbon intensity exist or are at varying stages of development. Some of these technologies were developed to avoid sinter iron and coke production, for instance relying on the direct reduction of solid iron (DRI) and using non-coking coal or gas as a reducing agent. The potential for using plastic waste as a reducing agent has been tested in some plants that have included this secondary feedstock to partially replace coke or coal in their operations (Vadenbo et al., 2013). While these innovative solutions promise reductions in the climate change impacts of primary steel production, commercial adoption is low (Hasanbeigi et al., 2014). The International Energy Agency estimates that the energy intensity of iron and steel production can still 
FIGURE 3.15 Impacts of the iron- and steelmaking sector (primary and recycled steel)
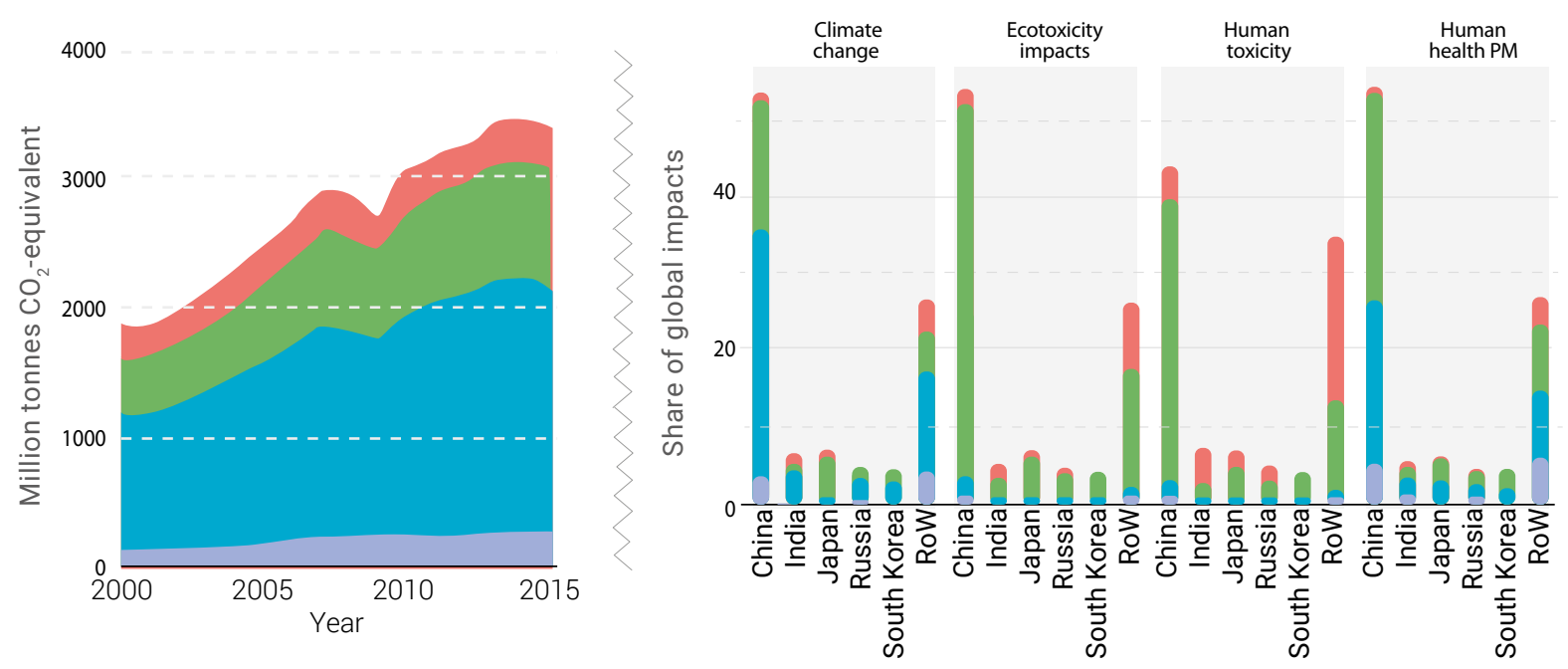

Dining Ironmaking Primary steelmaking Secondary steelmaking

Notes: Left: Temporal evolution of global greenhouse gas emission;. Right: Distribution of impacts (reference year 2015). The top 5 countries in terms of impacts are shown and the remaining regions are summarized in the category RoW (rest of world).

Data sources: BGS, global MFA database, ecoinvent 3.4, World Steel.

be lowered by 20 per cent compared to the current status if best available technology (BAT) is applied (IEA, 2014). Based on the Energy Technology Perspectives 2014 of the International Energy Agency (IEA, 2014), the Science Based Targets Initiative (Pineda et al., 2015) quantified the total $\mathrm{CO}_{2}$ emission budget between 2011 and 2050 for the iron and steel sector to be $112 \mathrm{Gt} \mathrm{CO}_{2}$, in order to stay within the safe operating space for climate change. Considering that global steel demand is projected to increase (IEA, 2014), such an absolute reduction in climate change impacts is a challenge.

Following steel, aluminium production is the metal industry with highest climate change impacts on the global scale. Most of the impacts come from the energy consumption of fuel and electricity, which are the respective drivers of the refining bauxite ore into alumina and of the subsequent smelting of aluminium via electrolysis. In 2017, average energy intensity for alumina refining and aluminium smelting were 23 per cent and 8 per cent lower than in 2000, respectively (International Aluminium Institute, 2018). Further energy savings of around 10 per cent are still possible on a global scale by phasing out outdated production facilities and adopting the best available technology. This point has been demonstrated by China in the last couple of decades, where production capacity has rapidly increased, providing the opportunity to install the newest technology and enabling the country to be at the forefront of aluminium smelting energy efficiency, with around 4 per cent lower electricity intensity compared to the global average (International Aluminium Institute, 2018). On the other hand, climate change and PM health impacts of aluminium production are highest in China because of the large amounts produced (54 per cent of global primary production in 2015 (International Aluminium Institute, 2018), but also due to the large carbon intensity of the electricity mix, which relies heavily on coal power.

For metals where the key input is electricity, such as primary aluminium and secondary steel, a shift towards an electricity mix with a higher share of renewables and a lower share of fossil fuels (in accordance with the Paris Agreement) will also favourably influence the impact. Moreover, if future growth in aluminium demand slows down, recycling can cover increasing shares of production (Van der Voet et al., 2018). which may substantially reduce the impact of metal production. Since recycled aluminium is currently the main form used in certain applications (mainly motor engines) and does not meet the quality standards of many other applications due to alloying elements, concerns have been raised that there may even be a scrap surplus in the coming decade if aluminium scrap continues to be processed as a mixed fraction (Modaresi \& Müller, 2012). This scenario of a scrap surplus may be unlikely as other uses for low-grade aluminium may be found (replacement of other materials), 
FIGURE 3.16 Share of global production amounts and environmental impacts of the aluminium production chain

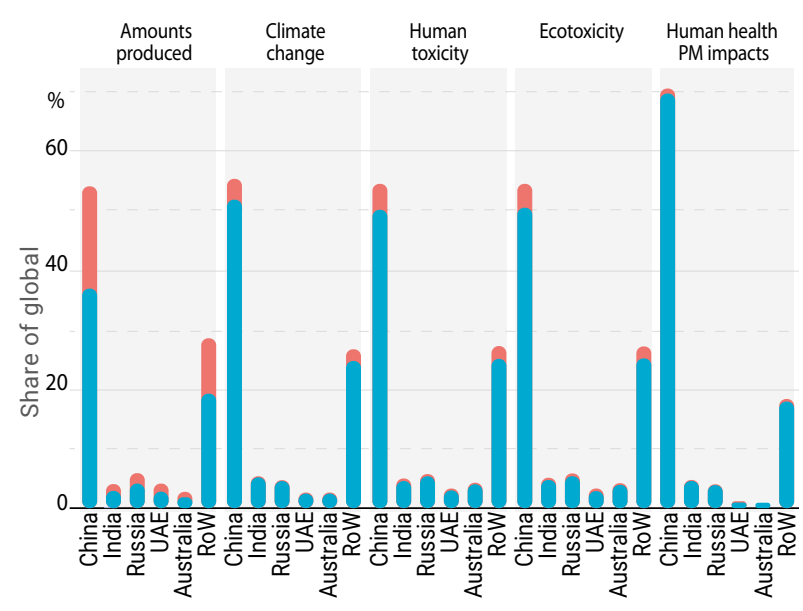

Drimary aluminium Secondary aluminium

Coupling data from BGS/global MFA database with regionalized ecoinvent 3.4 background data; reference year 2015

but these substitutions may result in fewer benefits than the substitution of primary aluminium. Therefore, attention should be paid to better sorting of scrap materials (Modaresi \& Müller, 2012), with a view to producing highquality secondary metals that can substitute the same primary metals.

While the above discussion refers to the industrial production of metals, there are also informal small-scale activities, especially in the mining sector in developing countries, which do not necessarily meet the technology standards assumed in the above figures. One of the most prominent examples is gold mining. To date, elemental mercury is still frequently used in (informal) artisanal and small-scale gold mining (ASGM) to extract gold (WHO, 2016). Artisanal and small-scale gold mining is estimated to be the largest anthropogenic source of mercury emissions, contributing approximately 37 per cent of the annual emissions in 2010 (AMAP/UNEP, 2013), and with an upward trend displayed in recent years (1,000 tons of mercury in 2008 versus 1320 tons or more in 2011 (Seccatore et al., 2014)). Recent estimates show that about 16 million miners (including around 4 to 5 million women and children) in over 70 countries, (mainly South America, Africa and Asia) may be directly affected by mercury exposure in ASGM (Pirrone \& Mason, 2009; WHO, 2016). Such exposure may cause various health issues including kidney dysfunction, neurological disorders/ symptoms and immunotoxicity/autoimmune dysfunction
(Gibb \& Leary, 2014; WHO, 2016), with the global burden of disease associated with ASGM miners estimated to be 1.22 to 2.39 million DALYs (Steckling et al., 2017). In addition to miners, their families as well as nearby and downstream communities may also be severely exposed to mercury via inhalation and/or ingestion of contaminated food items. As a response to the global concern over mercury, governments adopted the Minamata Convention in 2013, including objectives to reduce, and where feasible eliminate, the use of mercury in ASGM (Minamata Convention on Mercury, 2009).

Many alternative methods have been developed and are available on the market. For example, using "concentrate" amalgamation instead of "whole ore" amalgamation may reduce the use of mercury by a factor of up to 50 per unit of gold recovered (Ban Toxics!, 2010; Sousa et al., 2010; WHO, 2016). In addition, mercury in ASGM only yields about 20 to 30 per cent efficiency in recovering gold compared to 60 to 90 per cent from other methods (GEF, 2017). Therefore, miners have a financial incentive to switch, besides protecting their health. However, the sector's general informality is one of the root causes of mercury use, and results in difficulties for the miners to apply alternative methods (GEF, 2017): (1) miners often do not know about the alternatives; and (2) they have difficulty in accessing capital to finance the initial investments for switching to alternative methods. Formalizing the sector and supporting miners with knowledge, training and capital (for instance through micro-loans or income from higher prices of certified gold) may be promising actions in the combat against mercury emissions.

\subsubsection{Impacts of Non-Metallic Minerals}

Although non-metallic mineral resource extraction makes up more than 45 per cent of the total mass of extracted resources and displays one of the highest growth rates of all resource groups (figure 2.7 in chapter 2 ), its contribution in terms of impacts to climate change and other impact categories remains limited ( $<2$ per cent of the total resource impacts, figure 3.2, bottom). The majority of impacts of non-metallic minerals come from the processing stage, particularly from the production of cement and fertilizers (figure 3.17) (which are discussed in detail below). Extraction impacts are distributed among many different mineral resources. The main non-metallic minerals in terms of mass, namely sand/gravel and limestone, are of minor importance in terms of environmental impacts. 
Nevertheless, mining activities may have local impacts on ecosystems. In particular, sand is mined in large amounts from rivers and marine sources, causing damages to local ecosystems. This is mainly a consequence of bad management practice, which calls for the attention of policymakers. Using land-based sand mines (as long as not from living riverbeds) or mining rock and crushing it to gravel and sand are viable options for many countries (the additional energy demand for crushing stone is small in comparison to the total impact of non-metallic minerals).

Climate change impacts and PM health impacts increased with the mass of minerals extracted over time and were mainly spearheaded by cement production (figure 3.17). By contrast, the increase in toxicity impacts is smaller than the mass increase. In addition to cement, emissions from the application of phosphorus fertilizer are also relevant for toxicity (discussed in the box later in this section). Nitrogen fertilizers were not included in figure 3.17 (only phosphorus and potassium nutrients used as fertilizer or as feedstock), because nitrogen fertilizers are not produced from mineral resources but from nitrogen in air. However, note that the production of nitrogen fertilizers is energy intensive, consuming fossil resources, and would contribute more than 15 per cent to the total of each impact category shown in figure 3.17. Other neglected processes include the production of glass and ceramics (adding approximately 10 per cent to the total climate change impacts in Figure 3.17) and the processing of building stone.

The production of clinker, the main ingredient of cement, is responsible for the greatest share of climate change impact and a substantial ( $>40$ per cent) share of the other impacts (figure 3.17). Greenhouse gas emissions are primarily due to the direct release of $\mathrm{CO}_{2}$ in the process of decarbonation of the raw material during calcination in the clinker kiln, and secondly due to the use of fuels to cover the high heat demand necessary for the calcination process.

Similar to the impacts of steel and aluminium, the biggest shares of cement impacts occur in China and India (> 50 per cent and 13 per cent of global production in 2015 , respectively; see annex for data), due to the large build-up of infrastructure in the past several decades.

Since energy inputs represent roughly one third of the total production costs of cement, economic incentives have
FIGURE 3.17 Development of impacts from non-metallic minerals extraction and processing (values from 2000 indexed to 1)

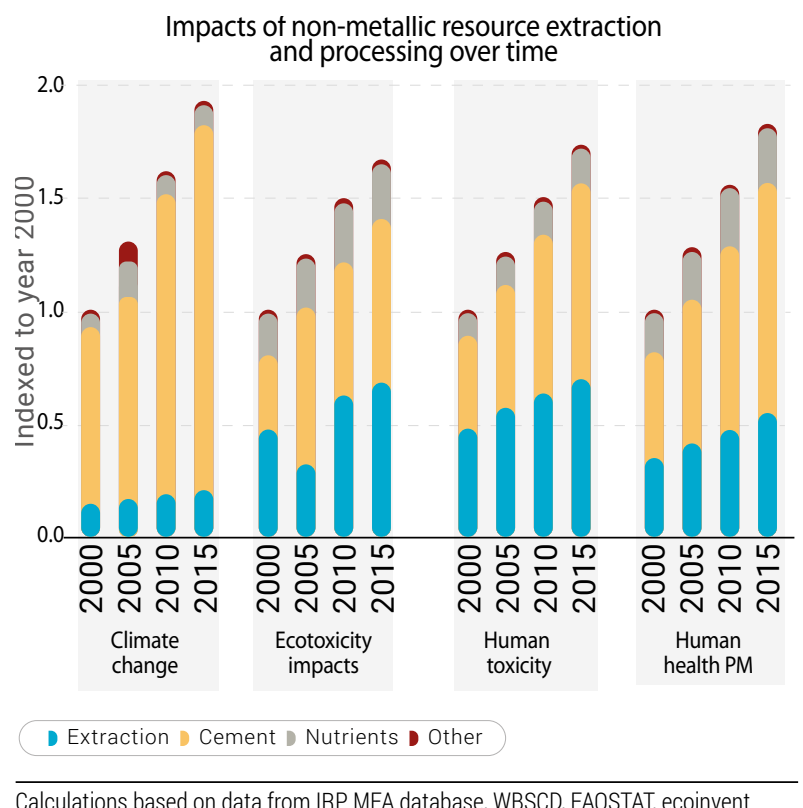

Calculations based on data from IRP MFA database, WBSCD, FAOSTAT, ecoinvent 3.4 (processing impacts include cement, fertilizer and brick production; glass and ceramics production were disregarded).

fostered early innovation in clinker kiln technology. Thermal efficiency has greatly improved in the last decades, thereby reducing the greenhouse gas emissions per $\mathrm{kg}$ of clinker. For instance, the heat demand of a modern precalciner kiln is only half of the heat demand of the now outdated, longwet kiln technology. As the technology reaches a state of maturity, the thermal requirements of modern kilns have plateaued in recent years and the adoption of efficient kiln technology stands at over 85 per cent of current installed capacity. While this is good news, it also means that the potential for further thermal efficiency gains is limited.

Another area for improvement of clinker production lies in the substitution of primary fuels and raw materials for waste materials. As part of the "Getting the Numbers Right" Project, the World Business Council for Sustainable Development (20 per cent coverage of global cement production) found that alternative fuels, biomass and mixed waste increased from a global share of 4 per cent of the heat demand of clinker kilns in 2000 to 15 per cent in 2015 (WBCSD, n.d.). Further increases can realistically be expected (IEA, 2018). Clinker production can accommodate alternative fuels and raw materials substituting primary fuels (such as coal or other fossil fuels) and raw materials (such as limestone), as long as requirements concerning chemical composition and heat 
demand are met. In most cases, the co-processing of waste materials (old tires, solvents and so forth) lowers the climate change impacts and, depending on the waste material and its introduction in the combustion process, may further decrease or increase other impacts, such as toxicity effects from airborne emissions. For example, clinker kilns can represent a viable way to treat organically polluted waste fuels because organics are destroyed due to the high kiln temperature. This is highly valuable, particularly in countries without proper dedicated infrastructure to treat hazardous waste. By contrast, waste raw materials such as organically contaminated soil are otherwise introduced at the "cold end" of the kiln and may be volatilized before they reach the hot zones, forming dioxin emissions. A careful evaluation of the types of waste materials to be co-processed is therefore necessary in the light of the kiln technology, the entrance point in the kiln and the gas purification system.

The increased demand for cement has overcompensated the reductions of greenhouse gas emissions per $\mathrm{kg}$ of clinker, leading to an absolute increase in overall impact (figure 3.17). Therefore, additional changes are necessary to decouple environmental impacts from economic growth. While improvements in the clinker production process are constrained by the fact that over half of the $\mathrm{CO}_{2}$-emissions come from the unavoidable calcination emissions of the raw material, the use of sustainable construction materials and an improved design could also represent important technology innovation pathways in the near and medium term. Often, a portion of clinker is substituted with other materials that have lower environmental impacts, like industrial by-products or waste materials (such as ash from coal power plants and blast furnace slag). Another option is to reduce the volume of concrete needed for a given construction process by using high-performance concretes (see, for example, Habert \& Roussel, 2009).

Although these strategies can help the cement industry meet the near- and medium-term $\mathrm{CO}_{2}$ emission reduction objectives, worldwide demand for concrete is expected to continue rising and at least partially offset the gains in $\mathrm{CO}_{2}$ intensity (WBCSD, 2018). Moreover, despite best efforts and technology, the fact that a large share of the $\mathrm{CO}_{2}$ emissions is related to calcination means that these associated emissions cannot be avoided. This is why the greatest share of future greenhouse gas savings is expected to come from installing carbon capture and storage, followed by a reduction of the clinker content in materials (IEA, 2018). Initial results have shown that a $\mathrm{CO}_{2}$ capture rate of 90 per cent is technically feasible with currently available technology, but it is also estimated to increase electricity demand (Cembureau, 2018).

Advances in materials can be combined with innovative production methods and technologies such as digital fabrication and construction. Concrete and steel can also be substituted with cross-laminated timber in the construction of mid-rise buildings. Furthermore, while the recycling of construction materials usually constitutes downcycling with little environmental benefit, this could change in the future if direct reuse of building components is introduced. Finally, urbanization design plays a key role in material demand for infrastructure. "Strategic intensification", as recommended in the IRP report (IRP, 2018c) can reduce material demand by establishing a "well-articulated networked hierarchy of high-density nodes that are interconnected", densifying cities and providing services to citizens at short distances, reducing mobility demand.

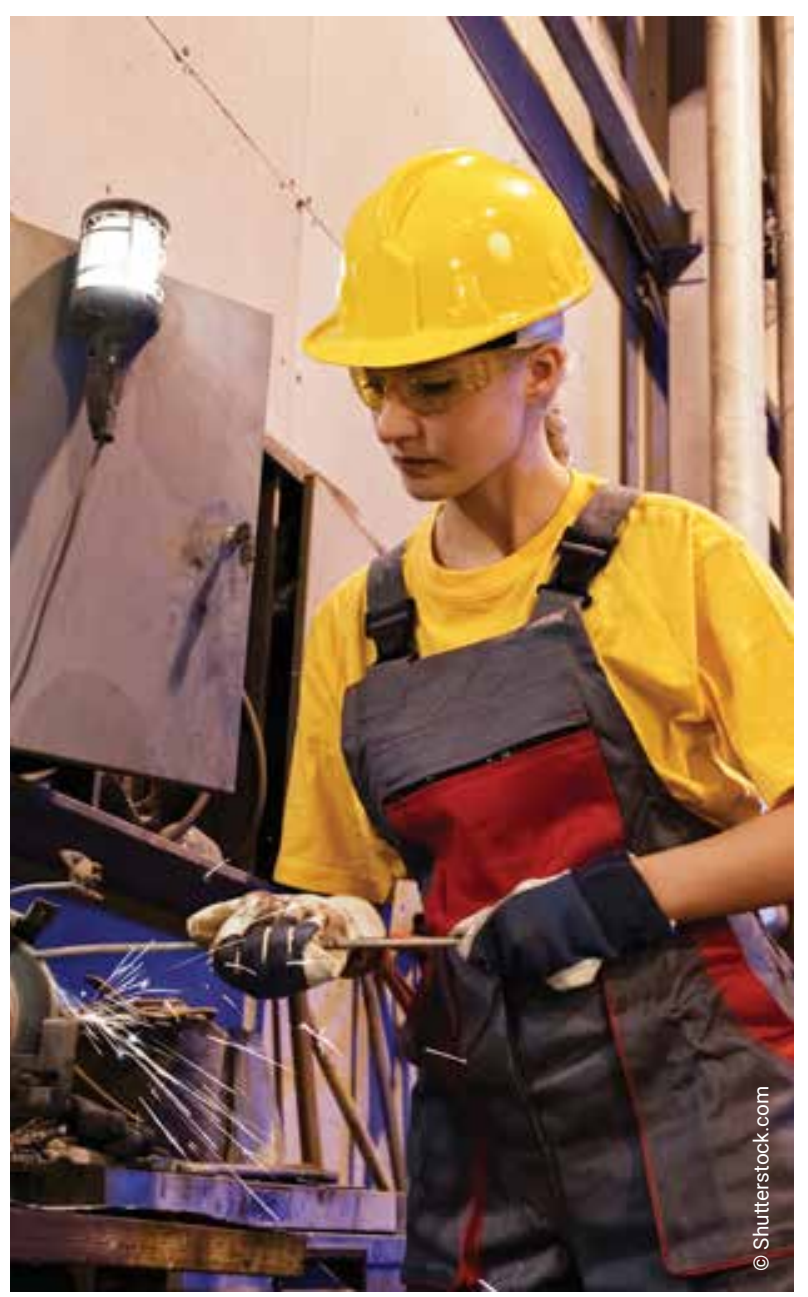




\section{BOX 3.2 Cradle-to-grave assessment of phosphorus fertilizer}

Fertilizer minerals play an important role in the context of global food security (IFA, 2002). In the case of phosphorus, a large proportion of globally applied fertilizer originates from phosphate rock resources. The main producing countries are the People's Republic of China, Morocco and Western Sahara, the United States of America and the Russian Federation (80 per cent of the total globally produced phosphate rock in 2015) (USGS, 2017). Initially alarming studies suggesting an upcoming phosphorus shortage and a threat to the global food supply have been put into perspective by a reclassification of phosphate reserves (USGS, 2012). Nonetheless, from an environmental viewpoint, it is vital to consider resource quality and the management of phosphorus resources.

Figure 3.18 shows a cradle-to-grave analysis of the global production and application of phosphate fertilizers involving phosphate rock mining, phosphoric acid production, fertilizer production and fertilizer application on agricultural fields. Climate change and particulate matter impacts result mainly from the production phase of fertilizer. Eco- and human toxicity effects are primarily caused by the contaminants in the fertilizer such as cadmium, uranium, chromium and other heavy metals. Application of contaminated phosphate fertilizers can lead to long-term accumulation of these metals in soil systems, where they may impact soil health and fertility, be taken up by crops or leach into water bodies (Kratz et al., 2016). Contaminants in the phosphate rock, such as heavy metals and radioactive substances, often end up in manufactured mineral fertilizers, while cleaner resources are mostly used as feedstock in the chemical industry. Improving the quality of applied fertilizer and reducing the application rate in countries with current over-fertilization are key to lowering the environmental impact. Pollutant thresholds for mineral fertilizers could be a suitable way of improving fertilizer quality. Resource-quality considerations (especially for cadmium and uranium) should also play a key role in future phosphorus mining activities. Contaminated production residues, such as phosphogypsum, are an additional source of environmental impacts (Tayibi et al., 2009). They are mainly disposed of in large stacks, where wind erosion and groundwater leaching may spread contaminants, or they are directly discarded in rivers or the sea. Moreover, fertilizer production requires numerous chemicals and has high material and energy needs.

Over-fertilization in agriculture causes eutrophication of rivers and lakes through runoff and leaching. Erosion is affected by land use change and agricultural management practices, but its eutrophying effects depend largely on the phosphorus content in the soil, which is increased through fertilizer applications. These human causes are often combined, and it is therefore difficult to separate the two effects. Phosphorus concentrations build up especially in agricultural areas that have been intensively managed for long periods. As a result, past fertilization leads to eutrophication through current erosion, which depends on current management practices (Scherer \& Pfister, 2015)

Table 3.1 summarizes the indices of phosphorus fertilizer use and related eutrophication impacts on a regional scale (FAO, 2018; FAO and World Bank, 2018; Scherer \& Pfister, 2016a). Results show that the relative eutrophication impact tends to be higher in developed and emerging economies (higher application rates), as well as in regions with vulnerable climate, soils and ecosystems such as the tropics. Latin America and the Caribbean and Asia and the Pacific show the biggest regional overall eutrophication impact of fertilizer application (table 3.1).

Both eutrophication and toxicity impacts could be lowered by avoiding over-fertilization. The high relative impact in Latin America results from the vulnerable ecosystems and high application rates. By contrast, in Sub-Saharan Africa soil nutrient depletion (or lack of fertilizers) is common (Sutton et al., 2013)' and yields could be increased by appropriate fertilization. Future projections point to a major increase in fertilizer use due to population growth. Increasing urbanization may additionally lead to nutrient flows far away from production areas and may thus limit reuse and recycling options (UNEP, 2016a). 
TABLE 31 Indices of phosphate fertilizer application and related eutrophication effects. The relative impact shows the magnitude of aquatic species loss per area of arable land (Azevedo et al., 2014; FAO, 2018; FAO and World Bank, 2018). Highest value per index is in bold. PDF: potentially damaged fraction of species (regional species loss).

CF: impact assessment characterization factor

\begin{tabular}{|c|c|c|c|c|c|}
\hline REGION & APPLICATION RATE & $\begin{array}{c}\text { AREA OF } \\
\text { ARABLE LAND }\end{array}$ & APPLIED AMOUNT & $\begin{array}{l}\text { CF FOR SOIL } \\
\text { EMISSIONS }\end{array}$ & RELATIVE IMPACT \\
\hline & [KG P205/HA] & {$[\mathrm{HA}]$} & [T P205/YR] & [PDF/KG P205] & [PDF/HA] \\
\hline Africa & 4.34 & $227^{\prime} 982^{\prime} 370$ & $988^{\prime} 628$ & $2.79 \mathrm{E}-13$ & 1.33E-12 \\
\hline Asia and the Pacific & 51.44 & $478^{\prime} 296^{\prime} 130$ & $24^{\prime} 604^{\prime} 563$ & $2.12 \mathrm{E}-13$ & $8.51 E-12$ \\
\hline EECAA & 4.83 & $124^{\prime} 872^{\prime} 800$ & $603^{\prime} 660$ & $4.98 \mathrm{E}-14$ & $2.31 \mathrm{E}-13$ \\
\hline Europe & 18.03 & $169^{\prime} 859^{\prime} 620$ & $3^{\prime} 062^{\prime} 363$ & $5.00 E-14$ & $9.89 E-13$ \\
\hline $\begin{array}{l}\text { Latin America and the } \\
\text { Caribbean }\end{array}$ & 33.89 & $166^{\prime} 857^{\prime} 520$ & $5^{\prime} 654^{\prime} 719$ & $3.84 E-13$ & $1.20 \mathrm{E}-11$ \\
\hline North America & 23.14 & $194^{\prime} 637^{\prime} 300$ & 4'503'709 & $9.00 E-14$ & $2.20 \mathrm{E}-12$ \\
\hline West Asia & 24.28 & $32^{\prime} 005^{\prime} 710$ & $777^{\prime} 105$ & $8.72 E-14$ & 1.36E-12 \\
\hline
\end{tabular}

Regarding innovation, technologies exist to purify phosphogypsum and therefore to enable it to be used (for example in the building sector) instead of being disposed of. However these are mostly not yet economical (Tayibi et al., 2009). Potential alternative sources, such as phosphate seabed mining (which is on an advanced planning stage in Namibia and South Africa) could lead to unknown damage in the marine ecosystem. Technologies that recover phosphorus from sewage sludge (ash) are being developed (Egle et al., 2016). Some of these technologies produce fertilizer that is cleaner than conventional mineral fertilizer and saves the extraction of primary phosphorus resources at the same time (Mehr \& Hellweg, 2018). Other measures include the recycling of organic wastes by anaerobic digestion or composting, in a circular economy approach, which is already currently practiced around the world (while retaining large upscaling potential). Depending on the wastewater infrastructure, urine separation could be a another way to recycle phosphorus for agricultural uses (Wu et al., 2016). Finally, many countries have made improvements in fertilization efficiency, leading to lower application rates and less eutrophication and ecotoxicity impacts without a reduction in yields. Precision agriculture is likely to further improve agronomic phosphorus efficiency in the future (Iho \& Laukkanen, 2012; Mallarino \& Schepers, 2005).

\subsubsection{Impacts of Fossil Resources}

Coal, oil and natural gas provide various forms of energy while also constituting the raw materials for numerous chemicals like pharmaceuticals, plastics, paints and many more. Extraction, processing, distribution and use are all major contributors to environmental pollution - especially in air.

A key pollutant in the extraction of fossil fuels is methane, as it contributes to climate change impacts. Coal extraction has particularly large impacts (figure 3.19), and is therefore discussed in more detail below. Generally, larger amounts of methane are bound in coal at greater depths, so underground mining releases more coalbed methane than open cast mining. Underground methane is vented to prevent the formation of explosive methane-air mixtures, but still causes human casualties throughout the world. In addition to flaring methane and converting it to $\mathrm{CO}_{2}$, recent technological advances enable methane to be captured and fed into local natural gas networks or used in gas turbines to supply mining equipment with electricity.

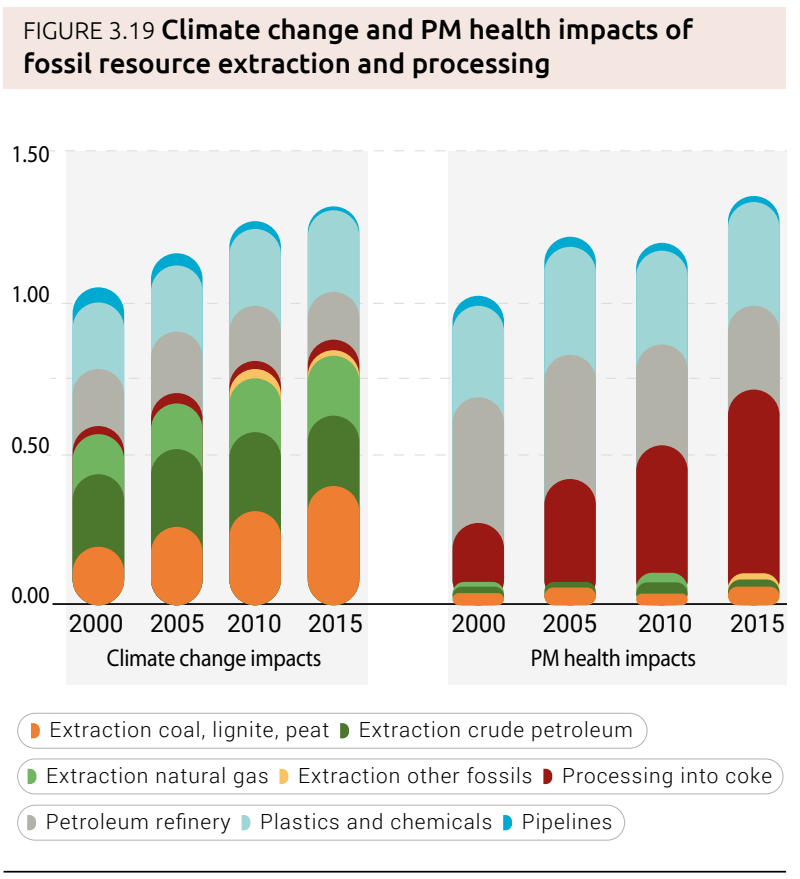

From Exiobase 3.4 (Exiobase, n.d.; Stadler et al., 2018). Impacts of the year 2000 indexed to 1. 
Polluting dust emissions occur from coal mining activities such as digging, blasting, coal handling and stockpiling, but also from increased wind erosion. This is relevant for underground and open-pit mining. The resulting emissions represent a health risk to workers and residents due to fine particulate matter release. Wet dust suppression and agglomerating agents are applied to the coal to reduce these emissions. Coal handling and stockpiling is increasingly taking place inside enclosures, which also helps to prevent leaching, keep coal dry and reduce noise pollution. In comparison to the particulate emissions from coal power plants, the share of health impacts from these emissions is small (figure 3.20), but may still have major local effects.

Crude oil and natural gas are recovered from deep wells. Moreover, unconventional extraction methods like shale oil and shale gas production (as well as production from oil sands) have gained interest in recent years due to technological innovation and the decline of conventional reserves. Overall, the total greenhouse gas emissions for oil and gas are in a similar range to that of coal extraction and processing impacts (figure 3.19). Mostly, they arise from venting, flaring and local energy supply, as well as from leaks and other sources of fugitive emissions (IPCC, 2006). Mercury is released into the environment during oil and gas extraction with wastewater and solid waste streams. These emissions are judged to be major sources of mercury contamination in oceans but currently lack quantification (AMAP/UNEP, 2013). Additionally, some of the mercury is separated after the extraction of fossil fuels and then released to the environment during artisanal and small-scale gold mining (see section 3.3.1). Environmental impacts from extraction of fossil fuels may also come from the release of other toxic compounds (such as those in drilling fluids) to air, soil and water bodies, as well as from seismic surveys and the construction of extraction infrastructure like ocean-floor pipelines.

The recent increase in unconventional oil and gas extraction in North America has brought additional environmental challenges that have not yet been fully quantified. Unconventional oil extraction, such as from shale or tar sands, is found to be on the higher end of greenhouse gas emissions in comparison to conventional deep-well extraction (IHS Energy, 2014). Natural gas fracking from shale may lead to gas leakage and methane migration into drinking water reservoirs. Additionally, the injected slickwater (a solution of water and chemicals) for enhanced recovery may reach upper layers of the earth and local aquifers, as well as consuming large amounts of water. Concerns about biodiversity loss from surface mining of tar sands have also been raised (Rooney et al., 2012).

The most impactful fossil processing step in terms of climate change impacts is the refining of crude oil into useful products (such as chemicals and fuels) (figure 3.19), primarily due to the large heat demand of this process. A key for human health effects and environmental impacts of acidification is the removal of sulfur from crude oil, which may cause acid rain and health effects from particulate matter formation during fuel combustion. A current technical challenge for global refineries is the new regulation on heavy fuel oil combustion for ships that will force refiners to produce ship fuel with 0.5 per cent sulfur by 2020, instead of the current level of 3.5 per cent. Several technical alternatives are being discussed to either produce compliant ship fuel or shift production to other products.

Fossil fuels, and coal in particular, are the main goods involved in global freight transport (UNCTAD, 2017). Global transportation of coal via ocean vessels has become more significant in recent years. The resulting environmental impacts are limited on the global scale but can be substantial on the local scale: for example, 28 per cent of Japanese coal particulate matter health impacts come from transport (figure 3.20). Improvements of related pollution impacts can be achieved with larger, more efficient ships and cleaner fuel. In addition to ship transport, oil and gas are distributed by pipelines, which can be problematic when causing fugitive emissions or spills. Maintenance, especially in remote regions, is essential to avoid leakages. Altogether, pipelines cause 3 per cent of the total greenhouse gas emissions from fossil fuel extraction and processing (figure 3.19), due to the energy demand for pumps and compressors and their fugitive emissions (particularly methane). 


\section{BOX 3.3 Use phase emissions and impacts of fossil fuel combustion}

Environmental and health impacts from the final use of fossil fuels play a crucial role in their life cycle. These impacts depend on the extracted resource quality, intermediate processing steps and the location of emissions, in addition to technical measures (for example flue gas cleaning equipment). Any mitigation actions must therefore consider the entire life cycle. Fuel properties vary largely (see coal in figure 3.21), and pollution therefore differs just as widely. For example, sulfur in fuel is converted into acidic $\mathrm{SO}_{2}$, and nitrogen is converted into NOx (fuel NOx). Both these air emissions act as precursors of secondary particulate matter, which leads to human health impacts, as well as causing terrestrial acidification. In the case of coal, part of the coal ash forms particulate matter and leaves the boiler with the flue gases. Coal washing and coking, typically applied to coal for the steel industry, remove impurities (for example sulfur), do prevent subsequent pollutant emissions in the use phase but come with trade-offs, such as increased energy demand and related emissions. Additionally, some power plants use the impure washing rejects and other waste coal (gangue), thereby simply shifting the point of emission to power plants near mines without leading to a total net reduction in pollution.

\section{FIGURE 3.20 Health impacts from primary and secondary particulate matter from coal electricity generation}

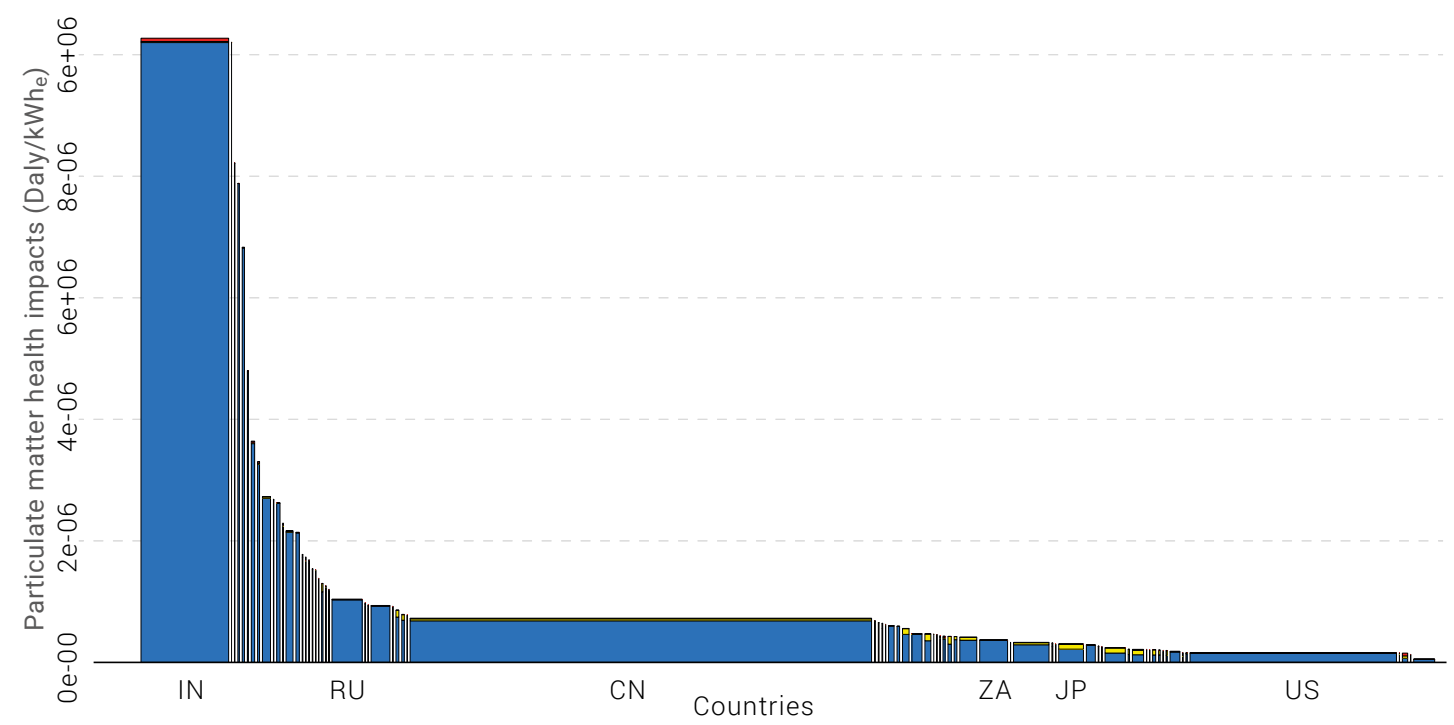

Dine D Transport Dower plant

The $x$-axis shows the electricity generation, with the width of bars being proportional to the kWh of coal electricity generated within each country. The $y$-axis shows the average health impacts caused by the coal power production of each country related to electricity from coal power plants (in DALY/kWh). The area of the bars is proportiona to total particulate matter health impacts from each country. Reference year: 2012. Regionalized health impacts were calculated with (Verones et al., 2016). Emissions of closed mines and spontaneous coal fires were not included due to lack of data.

Coal contributes 35 per cent to the anthropogenic emissions of mercury (Pirrone et al., 2010). There is large variation in the mercury share within raw coal composition (figure 3.21), and emissions can thus be prevented by sourcing coal with a low mercury content. Once released, mercury reversibly cycles between its different forms (two oxidation states and various organic forms, of which methylmercury is particularly toxic) and between environmental compartments globally. Post-combustion flue gas treatment eliminates considerable fractions of all forms of mercury pollutants, but health impacts from the fossil fuel use phase remain the highest in the entire supply chain (even in countries with modern flue gas cleaning systems) (figure 3.20).

Pollution prevention from fossil fuels is largely driven by environmental legislation (Lecomte et al., 2017). In the past few years, there have been major reductions of allowable emission concentrations in China and India, which are now two of the countries with the world's strictest emission limits. However, these emission limits are sometimes only applied to the newest plants (commonly the case in the United States of America and India), which may discourage innovation and modernization. In contrast, the Chinese government completely overhauled its electricity generation sector within one decade by shutting down old power plants and coal mines and replacing them with state-of-the-art ones. Furthermore, China equipped all its power plants with real-time monitoring devices to trace sources of pollution. Urban PM concentrations in China have dropped by 32 per cent in the last four years (Greenstone, 2018), but remain high due to the large amounts of coal used. 
Similar improvements would be possible in India, where power plants are often old and use outdated and incomplete flue gas treatment. This is particularly urgent as the population density in India is very high, meaning there is high exposure. An effective way to avoid placing unnecessary burdens on plant operators can be to adapt emission thresholds for pollutants with mostly local effects based on the surrounding population, such as in the case of $\mathrm{SO}_{2}$ in Japan, where emission limits are based on population densities for 19 different regions.

While there have been improvements in fossil power plant emission standards throughout the world, there has also been a dramatic increase in fossil electricity generation capacity in recent years, which contributes to increased access to affordable energy but has environmental and health trade-offs. Globally, the capacity increased by 73 per cent from 2000 to 2015 , with even higher increases in certain regions of the world (Lecomte et al., 2017). Due to high capital costs and long power plant lifetimes (sometimes exceeding 50 years), this poses the threat of a "lock-in" to environmentally harmful technologies. The construction of the least efficient subcritical coal power plants, which still make up the major share of new installations, has to be stopped to avoid compromising the achievement of global climate goals (World Steel Association, 2018), in line with SDG targets 7.3 and 7.a. Carbon capture and storage (CCS) is being discussed as an intermediate way to force the reduction of $\mathrm{CO}_{2}$ emissions from fossil fuel combustion, but comes with efficiency losses that will in turn push up fuel demand (Schakel, 2017) and increase other pollutant emissions for supply chains and facilities. Therefore, even with appropriate flue gas cleaning systems and CCS, fossil energy systems are bound to have substantial health and environmental impacts (UNEP, 2016c). Substitution of coal and other fossils with renewables appears to be the most effective way to lower the various types of environmental impacts (UNEP, 2016a, 2016c).

\section{BOX 3.4 Plastics - A Global Challenge and Opportunity for Sustainable Consumption}

Due to their low weight, durability and low cost, plastics have become one of the most used human-made materials. Global annual production increased from 2 million tons (Mt) in 1950 to $380 \mathrm{Mt}$ in 2015, roughly 2.5 times the average annual growth rate of global gross domestic product in the same period (Geyer et al., 2017). In contrast to the rapid increase in the production and diverse uses of plastics, the current management of plastics - particularly after the use phase - lags way behind: according to recent estimates from 2015, out of $6300 \mathrm{Mt}$ of all plastic waste historically generated, only around 21 per cent has been either incinerated ( 12 per cent) or recycled ( 9 per cent), whereas the rest ( 79 per cent) has accumulated in landfills or the natural environment (Geyer et al., 2017). This major loss of plastics from value chains not only reduces overall resource efficiency (4 to 8 per cent of oil was estimated to be used annually for global plastic production (Hopewell et al., 2009; World Economic Forum, 2016)), but has also led to substantial marine pollution (with recent estimates suggesting that 4.8 to $12.7 \mathrm{Mt}$ of plastic waste entered the ocean in 2010), particularly in the coastal areas of developing and transition countries in Asia (Jambeck, 2015). The adverse effects of plastics on marine ecosystems has been recently reviewed elsewhere (for example Thevenon \& Carroll, 2015; UNEP, 2016d; Worm et al., 2017).

Table 3.2 summarizes the major causes of the current mismanagement of plastics along their life cycle, highlights major (upcoming) challenges and outlines some opportunities for future actions and examples of existing initiatives for the sustainable consumption and production of plastics. Various factors in every stage of the plastic life cycle contribute to the current global mismanagement and resulting issues such as marine debris pollution. Therefore, holistic, transformative approaches throughout the entire value chain from production to waste management, in a circular economy approach, are needed. For example, one may argue that legal instruments that prohibit and/or use economic penalties to discourage microbeads and carrier bags, including those in operation in over 60 developing and transition countries in Africa, Asia, Oceania (including some islands states) and Central and South America (UNEP, 2018c; Xanthos \& Walker, 2017), may be extended to all countries and to other single-use plastics. 
The common practice of trading plastics for recycling is problematic, as it may result in higher environmental impacts when materials are sent from countries with a high technological level to countries using technologies with lower efficiencies, or even to informal recycling sectors in developing countries. Due to a lack of consistent characterization and reporting of traded waste, it is not currently possible to assess these additional environmental impacts associated with plastic waste trade. In 2016, about half of all plastic waste intended for recycling (14.1 Mt) was estimated to be exported by 123 countries, approximately half of which (7.35 Mt) was taken by China (Brooks et al., 2018). Since January 2018, China has implemented a new import ban on low-quality plastic waste, resulting in great pressure on countries exporting waste plastics. It remains to be seen if this change will lead to the build-up of more recycling infrastructure in the previously exporting nations or whether it will simply result in a shift of exports to developing or transition countries. One starting point for addressing the plastic waste trade may be the Basel Convention, which provides a framework for knowledge transfer and promotes the proper management of waste. While it is mainly hazardous waste that is regulated within this framework, plastics waste could also arguably be included, including the harmonization of technical standards and practices for treatment (Brooks et al., 2018).

TABLE 3.2 An overview of major causes, additional (upcoming) challenges and opportunities for future actions relating to the current mismanagement of plastics throughout their life cycle

\begin{tabular}{|c|c|c|c|}
\hline $\begin{array}{l}\text { LIFE CYCLE } \\
\text { STAGE }\end{array}$ & $\begin{array}{l}\text { MAJOR CAUSES OF PLASTICS } \\
\text { MISMANAGEMENT }\end{array}$ & $\begin{array}{c}\text { MAJOR } \\
\text { (UPCOMING) } \\
\text { CHALLENGES }\end{array}$ & OPPORTUNITIES FOR FUTURE ACTIONS AND EXAMPLES \\
\hline $\begin{array}{l}\text { Plastic } \\
\text { production }\end{array}$ & $\begin{array}{l}\text { - Rapid increase in production, } \\
\text { diversity, and complexity of virgin } \\
\text { plastics (and additives therein) } \\
\text { (UNEP, 2016d). } \\
\text { - Difficulties in identifying and } \\
\text { separating different plastics to } \\
\text { ensure quality, purity and safety, } \\
\text { thereby limiting plastic's circularity. } \\
\text { - Cheap prices linked to a low oil price } \\
\text { contribute to a steady demand for } \\
\text { virgin plastics (Kramer, n.d.). }\end{array}$ & $\begin{array}{l}\text { - Plastics } \\
\text { production may } \\
\text { further increase } \\
\text { - Expansion into } \\
\text { new markets } \\
\text { and new uses } \\
\text { for plastics } \\
\text { (Dauvergne, } \\
\text { 2018) }\end{array}$ & $\begin{array}{l}\text { - To develop and foster: } \\
\text { - Best production practices, including (1) reduction of harmful } \\
\text { substances and waste, (2) prevention of plastic pellet loss, (3) take } \\
\text { back, reuse and recycling of plastic products (i.e. transition to a } \\
\text { circular economy), and (4) transparency about ingredients and } \\
\text { production process, for example via clear global labelling, to enable } \\
\text { the sorting of plastics after use into high-value resource streams } \\
\text { (GESAMP, 2015) } \\
\text { - Prevention and reduction (for example by light weighting and new } \\
\text { materials) to do more with less plastic } \\
\text { - Expansion of existing initiatives to constrain fossil fuel supply, for } \\
\text { example the World Bank ending their support for new oil, gas and } \\
\text { coal extraction (SEl 2018) }\end{array}$ \\
\hline $\begin{array}{l}\text { Materials } \\
\text { and product } \\
\text { design }\end{array}$ & $\begin{array}{l}\text { A large portion of plastics ( } 36 \text { per cent } \\
\text { in 2015; (Geyer et al., 2017) is designed } \\
\text { for single use. Some uses lead to } \\
\text { direct releases of (micro)plastics into } \\
\text { the environment, for example, the } \\
\text { wash-off of microbeads in personal } \\
\text { care products and synthetic fabrics in } \\
\text { textiles (Browne et al., 2011), plus wear } \\
\text { and tear of tires. }\end{array}$ & & $\begin{array}{l}\text { To establish incentives (and disincentives) for: } \\
\text { - Reduction/elimination of single-use plastics, using, for example, } \\
\text { existing prohibition and discouragement via economic penalties for } \\
\text { microbeads and carrier bags in over } 60 \text { developing and transition } \\
\text { countries in Africa, Asia, Oceania (including some islands States), } \\
\text { and Central and South America as models (Xanthos \& Walker, } \\
2017 \text { ) } \\
\text { - Design of new materials and products for a circular economy (for } \\
\text { example minimized loss during use; easily reusable / recyclable; } \\
\text { more durable; streamlined variations of plastics types and } \\
\text { additives, using PET as a model) }\end{array}$ \\
\hline $\begin{array}{l}\text { Waste } \\
\text { generation }\end{array}$ & $\begin{array}{l}\text { A disposable / throwaway consumer } \\
\text { culture }\end{array}$ & & $\begin{array}{l}\text { To educate and incentivize consumers to reduce plastic waste } \\
\text { generation, for instance by using instruments such as bottle deposits } \\
\text { to increase collection of recyclables and by fostering responsible } \\
\text { disposal of non-recyclables. }\end{array}$ \\
\hline $\begin{array}{l}\text { Waste } \\
\text { management }\end{array}$ & $\begin{array}{l}\text { A lack of adequate management } \\
\text { systems for most plastic waste } \\
\text { worldwide (including collection, sorting } \\
\text { and recycling). In addition, much of the } \\
\text { plastic waste generated in developed } \\
\text { countries is exported to developing and } \\
\text { transition countries ( } 87 \text { per cent of all } \\
\text { exports of plastic waste since } 1988 \\
\text { (Brooks et al., 2018). }\end{array}$ & $\begin{array}{l}\text { The import ban } \\
\text { of waste plastics } \\
\text { by China since } \\
2018 \text { puts great } \\
\text { pressure on } \\
\text { many developed } \\
\text { countries that } \\
\text { previously } \\
\text { exported plastic } \\
\text { waste for } \\
\text { recycling (Brooks } \\
\text { et al., 2018). }\end{array}$ & $\begin{array}{l}\text { - Combine waste reduction methods with proper waste collection, } \\
\text { - } \text { disposal and treatment methods worldwide. } \\
\text { regulation of hazardous waste through the Basel Convention. } \\
\text { - Plastic landfill bans in } 11 \text { European countries to enhance recycling } \\
\text { (Worm et al., 2017). } \\
\text { - Define a set of clearly defined collection and sorting categories } \\
\text { - Extended Producer Responsibility (EPR), such as Norwegian } \\
\text { Regulation } 1289 / 2017 \text {. }\end{array}$ \\
\hline
\end{tabular}




\subsubsection{Impacts of Biomass Resources}

Biomass resources are used for food, material feedstock and for energy. Food is the most essential biomass extracted, as it is vital for humans and for SDG 2.4 (to end hunger). However, food production is also responsible for the majority of biodiversity loss, soil erosion and a large share of anthropogenic greenhouse gas emissions (UNEP, 2016a). Sustainable and productive agriculture is included in the SDGs in the form of indicator 2.4.1.

Food is mainly provided in the form of crops but also as animal products, which might be either wild catch (highly important for fish and SDG 14 but also wild game, insects and honey), from pastures (mainly ruminants) or feedbased production systems (mainly fish, chicken and eggs, pork and ruminants - including those bred for milk). Other animal biomass, such as insects or insect products (for example honey or silk), or mushrooms and algae can also be regionally important sources of biomass.

Crop yields per area have increased considerably over the last few decades (green revolution). However, growing population and increasing demand for high-quality food (including luxury products with a large biodiversity and water stress impact, such as coffee or cocoa) and cotton put pressure on water and land resources and add to eutrophying and toxic impacts through agrochemicals and fertilizer application (UNEP, 2016a). Land- and waterrelated impacts are further discussed in section 3.3.5 and freshwater eutrophication and toxicity from heavy metals from phosphorus fertilizers in box 3.2 .

In terms of climate change impacts, biomass extraction and processing account for more than 30 per cent of greenhouse gas emissions related to resources, not including emissions from land use change. Cattle farming has the highest share of direct emissions, mainly from enteric fermentation ( $\mathrm{CH}_{4}$ emissions) and $\mathrm{N}_{2} \mathrm{O}$ emissions, which also relates to the high impacts of the dairy sector. Rice production includes the highest $\mathrm{CH}_{4}$ emissions besides ruminants and has the highest impacts from crop production (figure 3.22). The upstream impacts of cattle meat, dairy products and paddy rice production account for 60 per cent of climate change impacts of biomass production and processing (without land use change). Direct greenhouse gas emissions of all biomass extraction and processing have the following causes: 53 per cent by $\mathrm{CH}_{4}, 26$ per cent by $\mathrm{CO}_{2}$ and 21 per cent by $\mathrm{N}_{2} \mathrm{O}$. Note that
FIGURE 3.22 Climate change impacts of biomass cultivation and processing, excluding land use change

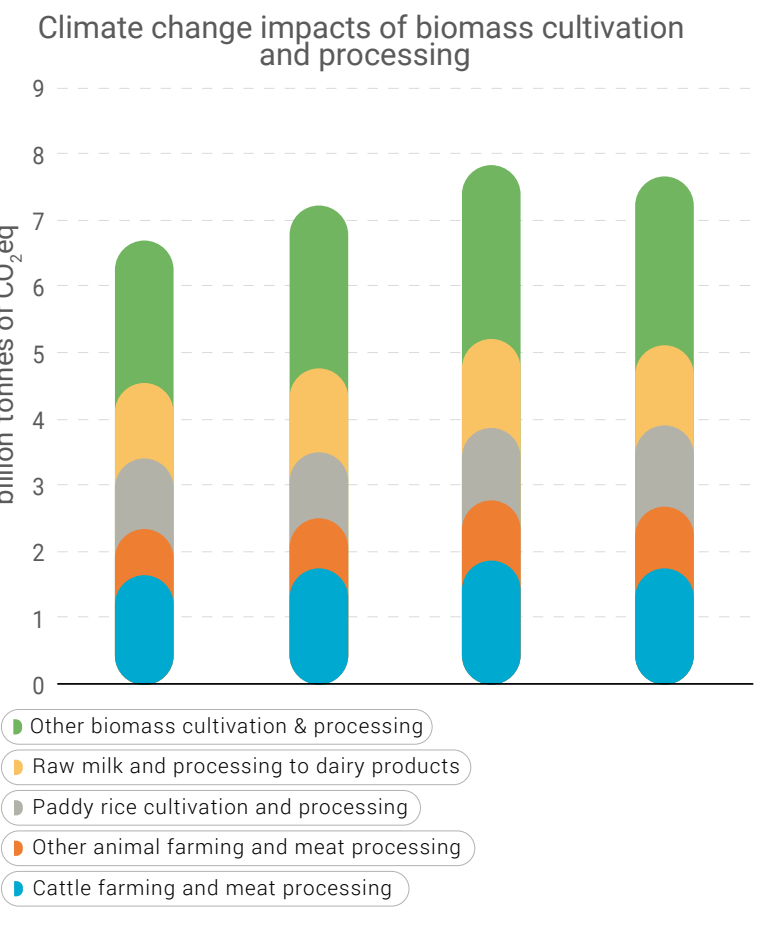

Exiobase 3.4 (Exiobase, n.d.; Stadler et al., 2018). Land use change is estimated to double the climate change impacts (to a total of 10.6-14.3 gigatons $\mathrm{CO} 2$ equivalents for the food sector) (UNEP, 2016a)

$\mathrm{N}_{2} \mathrm{O}$ emissions are highly variable and thus difficult to quantify on a global level, which leads to high uncertainties. Climate impacts of land use change are difficult to account for and allocate to sectors, but data from 2010 indicate that land use change potentially doubles the climate change impacts of biomass production (UNEP, 2016a).

From the production perspective, decoupling can be achieved through increased yields, as achieved in the previous century during the "green revolution". In many developing countries in particular, there is still a large potential for yield increases by using state-of-the art crop management, including optimized fertilization and irrigation practices (UNEP, 2016a). Genetically modified organisms (GMOs) are used to enhance yield and to save labour and agrochemicals, while at the same time being perceived as a potential risk to humans and ecosystems, as well as to production through the resulting herbicide tolerant weeds (UNEP, 2016a). Precision agriculture, new breeds and drone applications are promising technologies with the potential to further increase biomass production efficiencies globally. An example of precision agriculture technologies is found in chapter 5 (section 5.2.3.4). 
Greenhouse production can also increase yields by providing controlled and optimized growing conditions, especially for vegetables. Additionally, the efficiency of food production with regard to land and water resources (as well as emissions of agrochemicals) can be increased, but appropriate monitoring is still needed, since any efficiency gains can be offset by greater water depletion in some regions due to intensification (Ward \& Pulido-Velazquez, 2008). Increased irrigation efficiency can facilitate large-scale intensification of greenhouses, leading to an increase in total water demand in a region (for example Lake Naivasha in Kenya or southern Spain), even if the water demand per crop decreases. Moreover, greenhouse production requires additional material and, depending on the climate conditions, energy inputs. While the latter are often based on fossil fuels, there are greenhouses that run on renewable energy (such as heat pumps, geothermal heating, renewable electricity from wind and photovoltaics and so on). Some greenhouses also draw waste heat from industrial processes in the surrounding area.

Another important food category is the wild catch of fish and other aquatic species. Per capita fish consumption has increased by more than a factor of two since 1960. In the last few decades, this increase has mainly been covered by aquaculture as wild catch levels had stagnated due to depleted fish stocks (see FAO, 2016b for a discussion of overfishing impacts).

Consumption patterns are relevant in terms of demand, as current diets vary considerably between people and cultures. For the first time in history, however, the number of overweight people exceeds those experiencing hunger (partly due to a tendency for kilocalorie overconsumption). This overconsumption can be associated with additional resource use for both the additional, unnecessary food production and for dealing with the resulting health impacts. Meat and milk demand have increased largely over the last decades and has been responsible for higher environmental impacts. Higher-income countries consume on average five times more meat per capita and year than lower-income countries (McMichael et al., 2007). There might be benefits for nutrient cycling through some livestock activities, however these would be realized at a lower extent than current production levels. With reductions in the consumption of certain types of foods, such as processed foods containing trans fatty acids and red and processed meat products or paddy rice, both fewer environmental impacts and improved health can be realized simultaneously (Walker et al., 2018). However, this requires consumer knowledge about food choices and government policy to incentivize change.

Regional impacts of diets can vary depending on growing conditions, food preferences and season, which means diets optimized for an individual will be different depending on location (especially in the case of subsistence farming and limited trade activities, which is still the case for a large share of the global population in emerging and developing economies). In other areas, trade allows more independence from local conditions and could also help to improve global food production efficiency in case production is moved to the most suitable areas. However, global trade also leads to increased consumption of luxury products such as coffee, tea and cacao, which only grow in tropical regions and often induce considerable biodiversity impacts (Chaudhary et al., 2016a; Scherer \& Pfister, 2016b). Furthermore, trade among regions with unequal incomes and subsidies leads to distorted food prices, which do not reflect the full prices. This can lead to increased demand for food quantities or food types (such as meat) beyond nutritional requirements and thus add to food waste and overconsumption of calories or proteins. Note that personal dietary habits are a consequence of price, as well as other factors such as quality and taste (Glanz et al., 1998; Lappalainen et al., 1998). The role of culture strongly influences an individual's food choices as well, though their awareness of this influence may be limited (Kittler et al., 2012). While inducing changes in personal diets may be difficult to implement, they could help to mitigate the various environmental impacts of biomass resources and lead to health benefits at the same time.

Non-food biomass, such as wood, can also serve as feedstock for materials and energy. Material utilization ranges from the construction sector and furniture to packaging and various chemical applications, while the energy uses of wood include the residential and industrial sectors. Although wood is a renewable resource, its sustainable availability is limited. While overuse and deforestation are the norm in some countries, afforestation, reforestation and increasing wood stocks in existing forests are commonplace in others. This is often done intentionally to increase carbon storage in forests and mitigate climate change. The important role of afforestation (planting new forests) and reforestation (restocking of clear-cut forests) in carbon sequestration is undisputed, but the long-term success of harvesting 
less wood from forests by reducing forest management is debated in the literature (Werner et al., 2010; Krug et al., 2012): while initially the carbon pool in the forest increases, the rate of carbon uptake eventually declines, mortality increases in the long run and less wood is harvested and used in the economy to substitute other materials and fuels. Overall, models indicate that long-term carbon sequestration is highest when forests are harvested around their increment-optimized sustainable growth rate (for example Werner et al., 2010; Krug et al., 2012), and the harvested wood is used as a material or fuel (for example Seidl et al., 2007; Werner et al., 2010). Deforestation, on the other hand, results in severe environmental impacts due to loss of biodiversity, an increased risk of land degradation and carbon emissions (with deforestation causing up to 17 per cent of global carbon emissions (IPCC, 2007)). A main driver of deforestation is agricultural production, especially animal farming and soy/palm oil plantations, which cause between 70 per cent and 80 per cent of total deforestation globally. Other reasons include resource mining, infrastructure development, as well as timber logging itself. Illegal logging is assumed to account for 15 per cent to 30 per cent of all wood traded worldwide (Nellemann, 2012), a share that in the main tropical producer countries reaches 50 per cent to 90 per cent.

The biodiversity impacts of wood extraction depend largely on the intensity of forest management. While for extensive management systems (such as selection and retention forestry) no change in species richness is observed, intensive forestry (like clear-cut or slash and burn systems) can cause a loss of up to 50 per cent of local species (Chaudhary et al., 2016b). For the latter, biodiversity impacts in terms of species extinction is several orders of magnitudes higher in tropical regions than in Europe. It is therefore recommended to source wood from certified, extensively managed forests. However, only 8 per cent of forests worldwide are certified as sustainably managed, and over 90 per cent of these are located in Europe and North America (Nellemann, 2012). The climate targets of the Paris Agreement may result in increased bioenergy use (with or without carbon sequestration and storage) and intensification of forestry could increase, thereby impacting biodiversity.

The versatility of wood raises the question of how wood resources should be used in order to achieve an optimal environmental benefit. If sourced sustainably, the use of wood as a construction material or as material feedstock for products generally performs better in terms of climate change impacts compared to other material alternatives (Sathre \& Gustavsson, 2006; Sommer \& Kratena, 2017). Wood use is especially beneficial when high-impact products (like steel) are substituted and if a proper energetic use at the end of the life cycle is warranted (like replacing heating oil) (Suter et al., 2017). Furthermore, products with a long lifetime, such as buildings and furniture, store and thereby delay the emissions of carbon to the atmosphere, thereby reducing climate change impacts (Heeren et al., 2015; Mehr \& Hellweg, 2018). Although wooden buildings tend to have an increased space heating or cooling demand due to less thermal mass (and therefore less heat buffering capacity) than other materials such as brick or concrete, the overall life cycle impacts tend to be substantially smaller than those of massive buildings (Heeren et al., 2015). This is due to the environmental benefits of the material (carbon storage capabilities and less embodied energy) for impacts of climate change, but also for many other environmental indicators. It is now possible to construct modern multi-story buildings of (mainly) wood, which increases the application options in the building sector. A cascade use of wood in various successive product cycles can increase the efficiency and the environmental benefits of wood, especially when other materials and fossil energy sources are substituted (Höglmeier et al., 2015). Wood can also be beneficial if used as a fuel, but complete combustion and adequate flue gas cleaning must be ensured. Otherwise, outdoor exposure to pollutants such as particulate matter can be elevated, as for example measured in cities and municipalities with large shares of wood heating (Fuller et al., 2013). From a health perspective, indoor exposure from biomass use in households is even more relevant and represents one of the leading global health risks. On a worldwide level, approximately 3 billion people do not have access to clean fuels and cook with solid fuels (WHO, 2018b) such as wood, coal, charcoal and agricultural residue. This leads to unhealthy indoor pollution exposure and severe health impacts. The World Health Organization estimates that 3.8 million people die prematurely every year due to inefficient cooking practices and related exposure to pollutants (WHO, 2018b). This problem is addressed by SDG 3.9, which aims for a substantial reduction of the number of deaths and illnesses from pollution. Improved ventilation and a switch to clean cooking fuels are technical solutions to mitigate this problem. 
Biomass plays a large role as an energy source in future climate scenarios. However, wood should preferably be used firstly as a material before exploiting it as an energy source, as focusing on wood as an energy source alone would miss opportunities to make better environmental use of this resource. A comprehensive management strategy is needed, including a careful assessment of the environmental benefits and impacts of each biomass use, considering substitution effects of replacing other materials and fuels, cascade use and temporary carbon storage, in order to make optimal use of limited renewable biomass resources.

\subsubsection{Water Resource Impacts}

Freshwater is a vital resource for humans and ecosystems and thus a special case among abiotic resources. SDG 6 identifies several sub-goals for human access to freshwater, and under SDG 15.1 freshwater ecosystems ought to be sustainably used. The majority of water consumption occurs from renewable sources (rain, soil moisture, rivers, lakes and groundwater). Water scarcity is therefore mainly a function of demand and availability, which has been the basis for most approaches that quantify impacts in LCA (Kounina et al., 2013). If demand exceeds availability, non-renewable resources such as fossil groundwater reserves are tapped. In order to account for water scarcity beyond the common use-to-availability ratio (for example SDG indicator 6.4.2), the recent "AWARE" method, which was developed within a UNEP initiative (UNEP SETAC, 2016), includes natural scarcity and calculates the area required to sustainably supply a volume of water consumption in each of the $>11,000$ watersheds globally. In a subsequent step, the result is normalized to global equivalents, applying thresholds of 0.1 and $100 \mathrm{~m}^{3}$-eq $/ \mathrm{m}^{3}$ (with the indicator ranging over three orders of magnitude).

Water resources are mainly impacted by agricultural activities, but also by electricity production. Overall, cultivation and processing of biomass are responsible for almost 90 per cent of global water stress impacts (figure 3.2, right column). Interestingly, the regions with the largest water-stress production impacts (West Asia and Asia and the Pacific) have a higher water scarcity footprint for production than for consumption, which means they "export" scarce water mainly through food and cotton products to other regions such as North America, Europe and Africa (which are net importers) (figure
3.28). Increased efficiency in biomass extraction (yields) and supply (as discussed in section 3.3.4) will generally translate into reduced impacts on water. However, if a yield increase requires additional irrigation, water impacts will increase (but create benefits in terms of area decrease of land use and other impacts). Similarly, shifts in production areas might increase or decrease water consumptionrelated impacts, usually as a trade-off with land use impacts (section 3.3.7), as naturally productive areas can reduce water consumption but increase land use impacts, while increasing irrigated agriculture can reduce land use change and deforestation.

Besides agriculture, power production and iron making cause high shares of water consumption-related impacts. In thermal power and iron making, water is often consumed for cooling purposes and thus efficiency gains in production decrease water consumption. Furthermore, cooling technologies can be water efficient (or even, as in dry/air cooling, involve near to no water consumption at all), which might, however, decrease the efficiency of the system if its cooling power is reduced, leading to

\section{FIGURE 3.23 Resource-related water stress split by most contributing resource sectors (mostly agriculture)}

Total water stress split by industrial key sectors

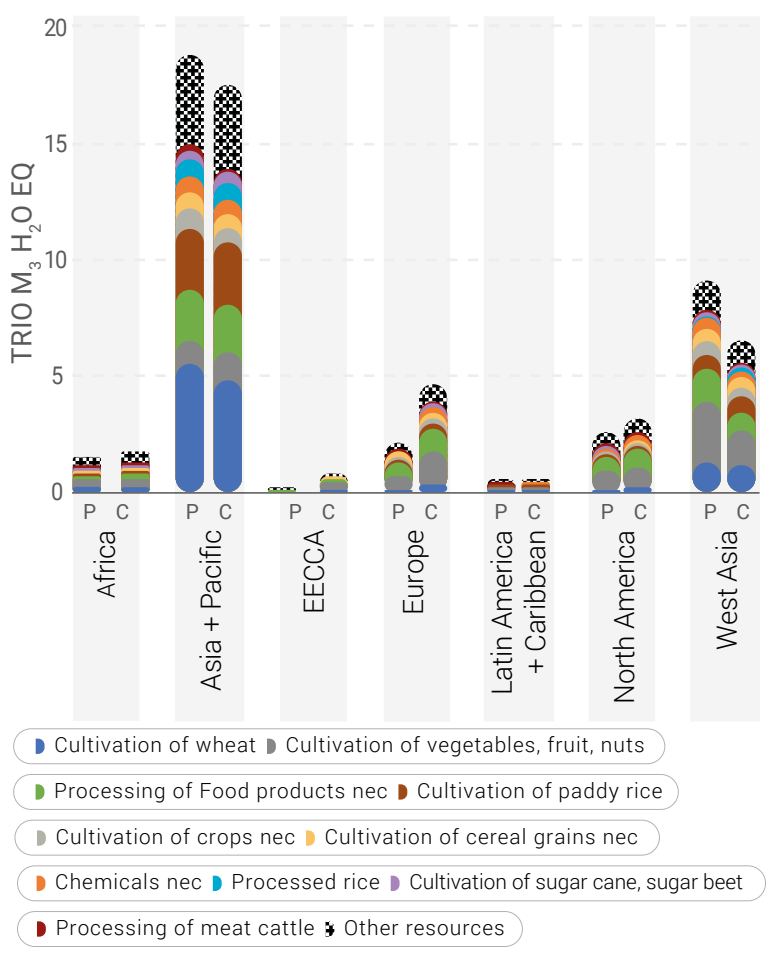

Assessed with the "AWARE" method (Boulay et al., 2018) per region and sector from a production (left column for each region) and consumption perspective (right column) 
trade-offs with other impacts associated with thermal power production or iron making.

Hydropower has also been shown to play a major role in water consumption impacts. However, proper management of hydropower dams can even help to mitigate water scarcity (which is not accounted for in figure 3.23). This also applies to water-storage systems other than hydropower (for example irrigation ponds). Additionally, fragmentation of the river and run-off regime changes may have a larger impact on aquatic ecosystems than water consumption (Scherer \& Pfister, 2016b).

\section{FIGURE 3.24 Biodiversity impact of land use in 2010 in per cent global species loss, summarized per ecoregion}

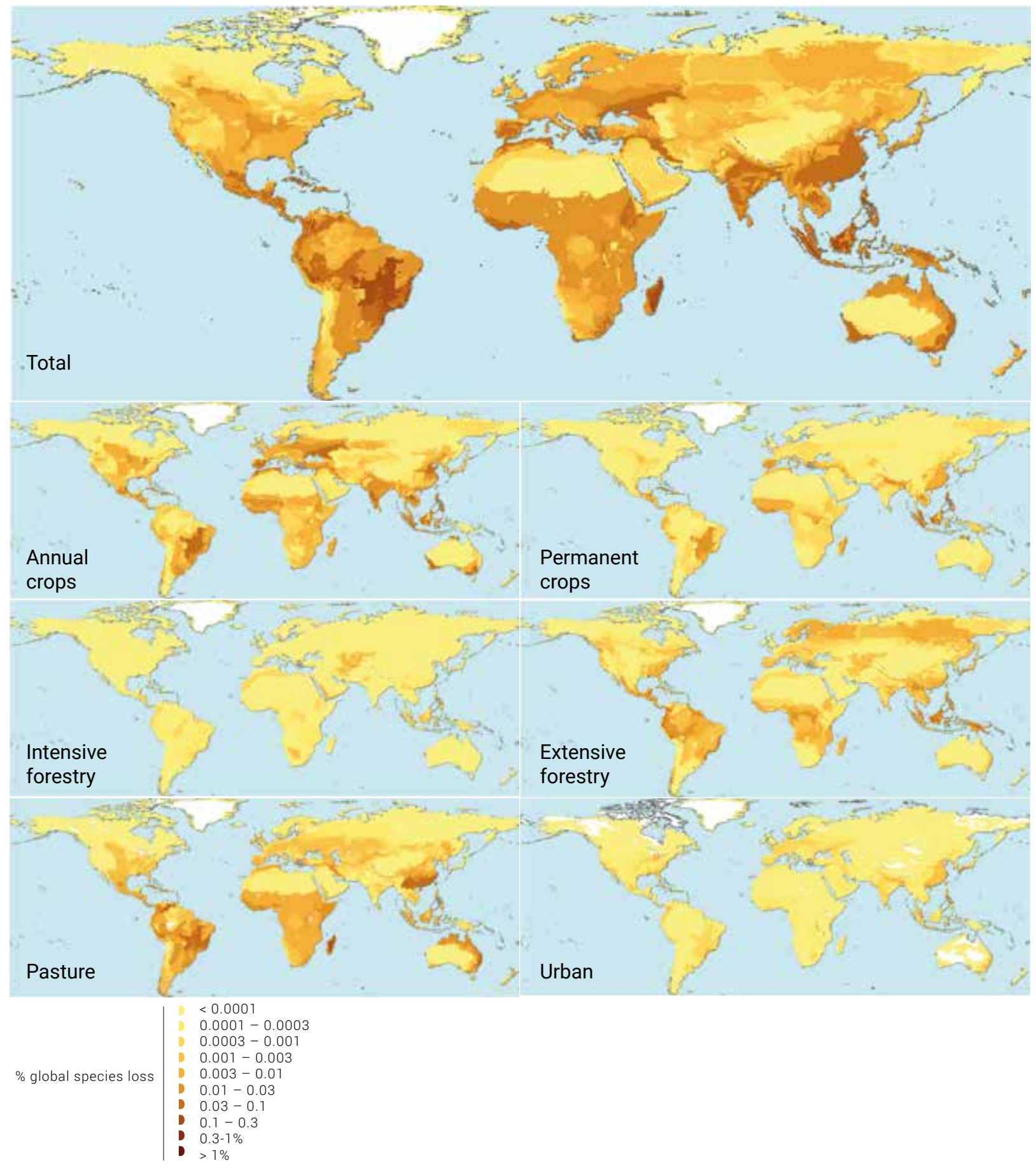

The impacts are calculated for total human land use (top map), as well as individual land use classes. Land use data from chapter 2 combined with biodiversity assessment Data sources: Chaudhary et al., 2015; UNEP SETAC, 2016 


\subsubsection{Land Resource Impacts (Biodiversity Loss)}

Land use gives rise to various environmental impacts including the destruction of natural habitats and biodiversity loss, as well as soil degradation and loss of other ecosystem services. The protection of terrestrial ecosystems is highlighted in various sub-goals of the SDGs (Wiedenhofer et al., 2018), and therefore efficient use and proper planning are required for land use change and management (Minx et al., 2013; UNCCD, 2017).

Land use caused global species loss of approximately 11 per cent by the year 2010. Figure 3.24 shows that the impact of total land use is highly correlated with agricultural activities. Islands and tropical areas have a high share of impacts due to their high endemic species densities, meaning higher shares of global species loss per local species loss. For total cropland use, annual crops have a higher share of the impact (2.9 per cent of global species loss) and are distributed over the globe, but particularly large losses of biodiversity are observed in the Indian subcontinent, Brazil, Central America, South East Asia, Eastern China, the Western Mediterranean region, Northern Black Sea shores and various parts of Australia. Permanent crop production (such as multiannual crops like coffee) causes total global species loss of 1.1 per cent. Pastures have a particularly high impact in South America, Africa, Madagascar, Australia and Southern China, and cause 2.8 per cent of global species loss in total. The highest impacts of forestry occur in Indonesia and the Philippines, as well as different parts of Latin America (2 per cent of global species loss). Urban areas have generally smaller land use-related biodiversity impacts ( 0.2 per cent of global species loss in total, figure 3.24) due to their limited extent compared to agriculture and forestry, but urbanization may alter consumption patterns and hence indirectly lead to changes in land impacts. Pasture-related impacts are highly uncertain, as the actual associated extent is difficult to estimate. Similarly, the extent and intensity of extensive forestry are uncertain. The impact of mining is small in comparison to other land uses (IRP, 2017a), but it can lead to local biodiversity loss, especially because some mining sites are located in valuable and vulnerable ecosystems. This includes large mining projects as well as informal mining activities in rainforests. In addition to direct land use, there are also biodiversity impacts from building streets and cities in remote mining areas. Furthermore, increasing resource demand and depletion of easily accessible reserves pushes up mining activities in remote areas, including tropical forests and fragile areas (Allegrini et al., 2015; IRP, 2018a).

Many industrialized regions such as Europe, parts of the United States of America and Australia show decreasing land use impacts (figure 3.25), while others regions such as Indonesia, the Philippines, Brazil, tropical Africa and Peru see increasing land-use impacts. Many of these expansions occur in ecoregions with high species loss intensity (measured as per cent global species loss per km² in each ecoregion, see figure 3.25). Note that biodiversity loss and recovery are processes in time. Long-term species loss at steady state was assessed here, but species loss from additional land use may not occur right after the change. Biodiversity recovery is also not instantaneous and may occur over long time periods (Curran et al., 2014). Between 2000 and 2010, while overall biodiversity impacts due to land use were fairly stable in the present analysis (based on chapter 2), the effects on regions with increased and decreased biodiversity (figure 3.25) do not necessarily outweigh each other. In fact, the significantly increased losses in many regions are alarming. Calculations based on other land-use data show that global biodiversity losses increased between 2000 and 2010, as documented in the previous edition of this report (IRP, 2017a). The reason for the discrepancy in assessing the trend of biodiversity loss lies in the uncertainty in land-use data, which can be based on statistics (for example of FAO), remote sensing data or a combination of both (as used in chapter 2). Remote sensing can provide a detailed assessment of total extent, but changes over the years are affected by high uncertainty due to the resolution of the image and the varying climate. Note that agricultural management intensity also influences biodiversity, which was not considered in the present section and impacts are therefore underestimated in this respect. On the basis of all the above, it is evident that continued attention and efforts are required to achieve the goals of SDG 15.5 to halt biodiversity loss, as well as the Aichi goals of the Convention on Biological Diversity to reduce the direct pressures on biodiversity and promote sustainable land use. Resources, especially biomass extraction, play a central role in this endeavour. Since the impact per $\mathrm{m}^{2}$ of land use varies geographically and by management intensity, Maron et al. (Maron et al., 2018) proposed to set up a series of area-based, quality-specific area targets for land use, which address protected areas and also used areas. 
The results of this analysis support the findings of IPBES for the four world regions (Africa, Americas, Asia and the Pacific, and Europe and Central Asia (IPBES, 2018): in general there is a strong decline of biodiversity related to land use, but several regions have also been able to recover biodiversity. The high variability requires detailed assessments, including into vulnerability to loss of ecosystem services (which is especially high in Africa).

Land use also affects soil systems. Soils are important environmental assets, particularly given the need for additional food for a growing future population and for the achievement of the SDGs (IPBES, 2018). SDG 15.3 addresses this need by establishing land degradation neutrality as a global objective to be addressed at local to national levels. The United Nations Convention to Combat Desertification is promoting a number of initiatives to address SDG 15.3, in addition to its related ongoing work on drought and desertification. Land Degradation Neutrality has been defined by the Parties to the Convention as: "A state whereby the amount and quality of land resources, necessary to support ecosystem functions and services and enhance food security, remains stable or increases within specified temporal and spatial scales and ecosystems" (UNCCD, n.d.). Achieving land degradation neutrality requires an evaluation of the land potential (UNEP, 2016e). The recommendation is to adapt land use and management to this potential, such that the crops and production systems need to correspond to soil properties so they provide optimal yields with minimal degradation impacts. Systems, strategies, and tools for land evaluation are reviewed and presented in a previous IRP report (UNEP, 2016e). Land/soil degradation includes several degradation processes (for example erosion, compaction, salinization or acidification) and harms biotic productivity and the capacity of the land to deliver other ecosystem services (UNEP, 2016e). While land evaluation helps to predict which types of production systems are likely to cause such harm on which types of land (UNEP, 2016e), the environmental impacts of soil degradation have not yet been adequately quantified, for example by Life Cycle Impact Assessment methods (Vidal Legaz et al., 2017). Nevertheless, on a case study level, results show that productivity losses can be substantial. Compaction, for example, can lead to relative yield losses of up to double-digit percentages in the first few years after compaction stress and losses remain in the order of one-digit percentages in the long term (Håkansson \& Reeder, 1994). Crops and production requiring intensive tillage and frequent tractor impacts associated with fertilizer and pesticide application (for example large scale potato production), increase compaction risk, particularly on soils with high clay and moisture content (Stoessel et al., 2018). Technological innovation therefore potentially leads to higher compaction risk, due to the trend towards more and larger machinery use. On the other hand, some innovations, such as those applied through precision farming, can reduce machinery passes on the field, and, in the future, agricultural robots could substitute the use of heavy machinery while lowering fertilizer and pesticide inputs (which are essential in no-till farming).

Other forms of degradation that have been shown to cause significant yield reductions include erosion-driven soil organic matter losses, salinization, soil acidification and reductions in soil fertility driven by removal in crops and crop residues. Few other degradation processes have been strongly linked to yield or productivity losses but remain at the level of proxy indicators. The main single indicator used for soil "quality" in LCIA is soil organic carbon or soil organic matter (Milà i Canals et al., 2007), but this has not yet been applied to global agriculture, although it is one of the three indicators selected by the UNCCD to quantify SDG 15.3. Since productivity losses due to various soil degradation processes have not yet been consistently assessed at the global level, they are not assessed in this report. However, some of the existing tools for quantifying degradation, for example the Revised Universal Soil Loss Equation (RUSLE), give a clear indication about good agricultural practices: Panagos et al., 2015, estimate that contour farming may reduce (water) erosion rates by up to 40 per cent, while no-till practices may reduce them by up to 75 per cent on some soils and slopes. Prevention of soil erosion is mentioned alongside prevention of overgrazing, maintenance of soil organic matter content and maintenance or introduction of landscape elements providing ecosystem services as an option for more sustainable land use in a previous IRP report (UNEP, 2016a). 
FIGURE 3.25 Biodiversity impact of total human land use in 2010 normalized to area (in per cent global species loss per million $\mathrm{km} 2$ ), summarized per ecoregion

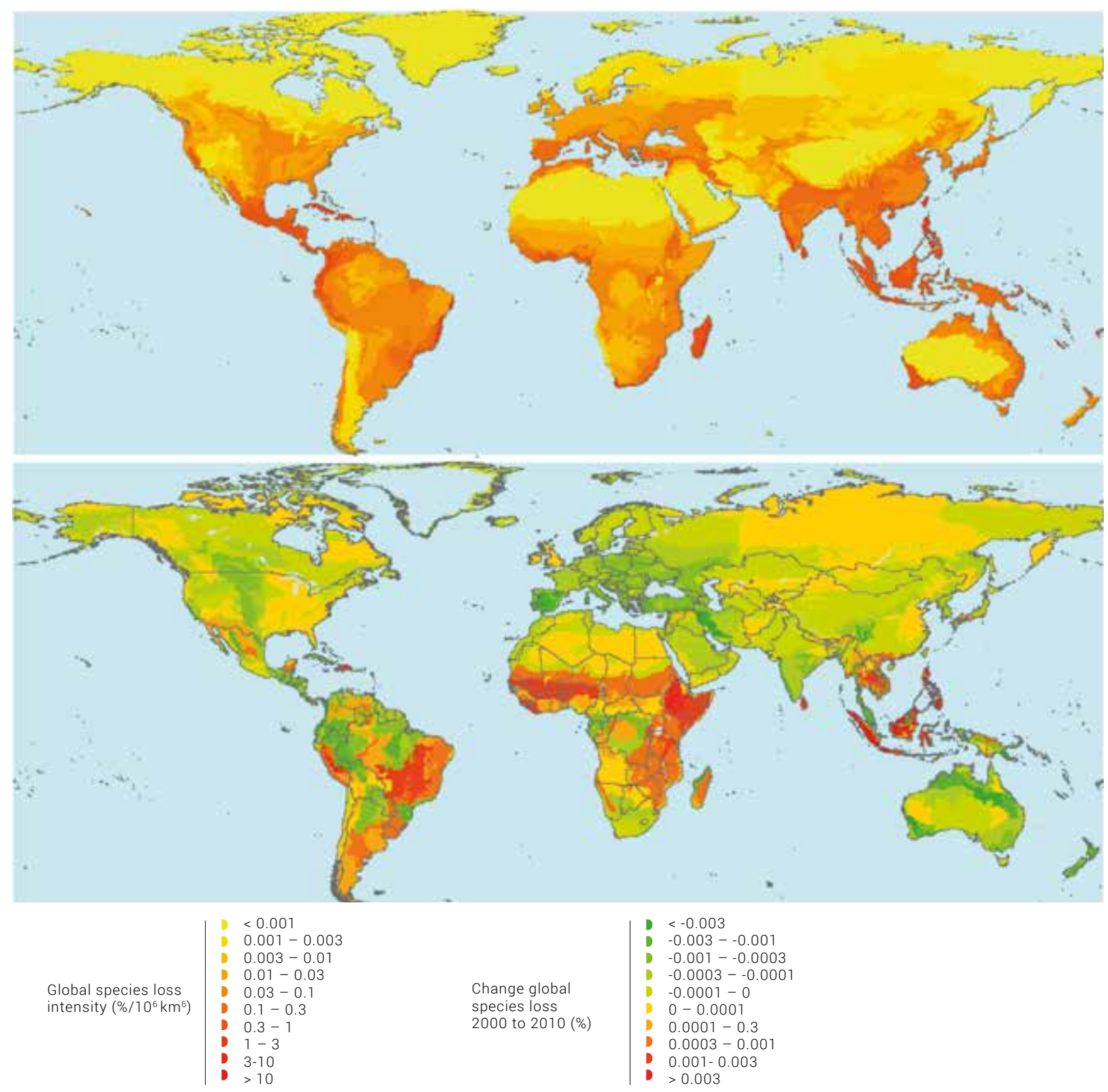

Land use data from Chapter 2 combined with biodiversity assessment (UNEP-SETAC 2016a) 


\subsection{Conclusions}

This chapter has described the impacts of natural resource extraction and processing and, in selected cases, extended this coverage to economy-wide impacts. Natural resource extraction and processing make up approximately 50 per cent of total GHG emissions. For water stress and biodiversity loss due to land use, the share resourcerelated impacts of the total economy-wide impacts are even larger than 90 per cent, mostly driven by agriculture. An estimated 11 per cent of global species were lost by 2010 due to global land use, while the consumption of water contributes to water stress, thereby threatening the sustainable supply of freshwater to humans and ecosystems (UNEP SETAC, 2016). In addition, while some low-income regions suffer from soil nutrient depletion, the overuse of fertilizers leads to eutrophication as well as ecotoxic effects in many other regions (with both ultimately leading to biodiversity loss).

Between 2000 and 2015, there was a relative decoupling of resource-related environmental impacts from GDP and also a moderate relative decoupling of impacts from the extracted mass of resources. However, impacts still increased on an absolute scale, as did global average per capita climate change and health impacts. Climate change impacts increased by a factor of 1.4 between 2000 and 2011 , following a similar trend to that of total extracted mass of resources (increasing by a factor of 1.6). During the same time, water- and land use-related impacts also increased, but by a lesser degree (by a factor 1.2 for water stress) due to increased productivity in food production, whereas resource-related value added doubled. If the rising trend in resource-related impacts persists, the goals of the Paris agreement will become difficult to meet and the achievement of the Sustainable Development Goals, including SDG 15.5 to halt biodiversity loss, will be put at risk.

The impacts and value creation are not equally distributed around the globe. Per capita impacts of high-income regions are between three and six times larger than those of low-income regions. This is reinforced by trade. For example, Europe and North America outsource environmental impacts, such that a part of the total environmental impacts of consumption occurs abroad. At the same time, the value created through these traded materials in the countries of origin is relatively low.
Capital investments for the build-up of infrastructure were the main driver of resource use in emerging economies, while in industrial countries consumer goods dominate final demand. While general trends exist, such as increased impacts with increased income, there are also cases of low-emission households within high-income segments - showing that decoupling is possible.

Environmental impacts are not always correlated with each other, indicating that a set of indicators is needed to assess resource-related impacts in a comprehensive manner and avoid problem shifting. Potential measures of the simultaneous reduction of several impacts include food waste reductions and shifts in diets towards less meat and animal products from intensive livestock systems. Phasing out coal as a fuel reduces climate change impacts and also other impacts related to resource processing. Focusing on long-term material use of sustainably grown wood, in particular in the construction sector, can lead to co-benefits in terms of climate change and biodiversity loss. Similarly, conserving valuable forest ecosystems and avoiding deforestation contribute to reducing climate change and biodiversity impacts. However, if climate policy leads to increased use of bioenergy (combined with Carbon Capture and Storage as a negative emission technology), as foreseen in many climate scenarios, additional biodiversity loss may occur through an increase in intensive biomass production. Special attention is therefore needed to avoid problem shifting from mitigating climate change to accelerating biodiversity loss.

Overall, this chapter illustrates that further action is needed to reach absolute decoupling and remain within planetary boundaries. While improvements in processing technologies have greatly reduced impacts in the past, this trend has plateaued in recent years for some key materials and further efficiency gains are limited in potential. Therefore, a systemic change is needed. The future of innovation lies particularly in the efficient design and use of materials, following circular economy principles. Chapter 4 will explore scenarios for a sustainable future, and chapter 5 will discuss policy measures to foster this development. 